\title{
International climate policy architectures: Overview of the EMF 22 International Scenarios
}

\author{
Leon Clarke ${ }^{\mathrm{a}, *}$, Jae Edmonds ${ }^{\mathrm{a}}$, Volker Krey ${ }^{\mathrm{b}}$, Richard Richels ${ }^{\mathrm{c}}$, Steven Rose ${ }^{\mathrm{c}}$, Massimo Tavoni ${ }^{\mathrm{d}, \mathrm{e}, \mathrm{f}}$ \\ ${ }^{a}$ The Pacific Northwest National Laboratory (PNNL), Joint Global Change Research Institute (JGCRI), at the University of Maryland College Park, USA \\ ${ }^{\mathrm{b}}$ International Institute for Applied Systems Analysis (IIASA), Austria \\ ${ }^{c}$ Electric Power Research Institute (EPRI), USA \\ d Princeton Environmental Institute, Princeton University, USA \\ e Fondazione Eni Enrico Mattei (FEEM), Italy \\ ${ }^{\mathrm{f}}$ Centro Euro-Mediterraneo per i Cambiamenti Climatici (CMCC), Italy
}

\section{A R T I C L E I N F O}

Available online 24 October 2009

Keywords:

Climate Change

Scenarios

Stabilization

International Participation

Overshoot

\begin{abstract}
A B S T R A C T
This paper presents an overview of the study design for, and the results of, the EMF 22 International Scenarios. The EMF 22 International Scenarios engaged ten of the world's leading integrated assessment (IA) models to focus on the combined implications of three factors integral to international climate negotiations: (1) the long-term climate-related target, expressed in this study in terms of the $\mathrm{CO}_{2}$-equivalent $\left(\mathrm{CO}_{2}\right.$-e) concentration associated with the GHGs regulated under the Kyoto Protocol, (2) whether or not this target can be temporarily exceeded prior to 2100 ("overshoot") allowing for greater near-term flexibility, and (3) the nature of international participation in emissions mitigation. The EMF 22 International Scenarios are based on combinations of these dimensions, embodied in ten specific climate-action cases that all modeling groups in the study attempted to represent.
\end{abstract}

(C) 2009 Elsevier B.V. All rights reserved.

\section{Introduction and background}

Stabilizing the global climate will require substantial reductions in emissions of all greenhouse gases (GHGs). Indeed, emissions of the most important anthropogenic GHG, carbon dioxide $\left(\mathrm{CO}_{2}\right)$, must eventually approach zero to stabilize atmospheric $\mathrm{CO}_{2}$ concentrations. It will be impossible to achieve reductions of this degree, and therefore to achieve stabilization, without comprehensive international action.

The challenge of deep emissions reduction stands in sharp contrast to present emissions mitigation around the world. Both near- and long-term policies are still under development throughout much of the world; those policies in place are characterized by varying approaches and levels of ambition. Yet, the majority of literature on GHG stabilization is largely predicated on the assumption that all nations take actions immediately, reducing emissions whenever and wherever it is cheapest to do so (e.g., the majority of the mitigation scenarios in Fisher et al., 2007 and Clarke et al., 2007). Hence, a practical question is how to proceed in the nearterm with differentiated degrees of mitigation while still treading on a path toward long-term, climate-related targets (e.g., a $2{ }^{\circ} \mathrm{C}$ increase in global mean surface temperature relative to preindustrial levels ${ }^{1}$ ).

\footnotetext{
* Corresponding author.

E-mail address: leon.clarke@pnl.gov (L. Clarke).

${ }^{1}$ For the remainder of this document, the term "temperature" refers exclusively to global mean surface temperature. "Temperature increase" refers to the increase in global mean surface temperature relative to preindustrial levels.
}

The purpose of the EMF 22 International Scenarios is to address this question. The EMF 22 International Scenarios engaged ten leading integrated assessment (IA) models from around the world to focus on the combined implications of three factors: (1) the long-term climaterelated target, expressed in this study in terms of the $\mathrm{CO}_{2}$-equivalent $\left(\mathrm{CO}_{2}-\mathrm{e}\right)$ concentration associated with the GHGs regulated under the Kyoto Protocol $\left(\mathrm{CO}_{2}, \mathrm{CH}_{4}, \mathrm{~N}_{2} \mathrm{O}\right.$, HFCs, PFCs, and SF6), ${ }^{2}$ (2) whether or not this target can be temporarily exceeded prior to 2100 ("overshoot") allowing for greater near-term flexibility, and (3) the nature of international participation in emissions mitigation. The EMF 22 International Scenarios are based on combinations of these dimensions, embodied in ten specific climate-action cases that all modeling groups in the study attempted to represent.

Within this context, the EMF 22 International Scenarios provide insights into such questions as: How aggressively should developed countries such as the U.S. and E.U. act given expectations about action in emerging economies such as India and China? What long-term targets are possible based on mitigation levels currently being debated or planned in the developed regions? What will be the near-term and longterm economic consequences of meeting particular climate-related

\footnotetext{
2 The $\mathrm{CO}_{2}$-e concentration is the concentration of $\mathrm{CO}_{2}$ that would lead, by itself, to the same impact on the Earth's radiative balance as the combined concentrations of a group of radiatively-active substances (Fisher et al., 2007). In this paper, unless otherwise noted, $\mathrm{CO}_{2}$-e concentrations refer to the combined effects of the Kyoto gases. Note that this paper also discusses the emissions and implications of non-Kyoto substances, such as the gases regulated under the Montreal Protocol and aerosols.
} 
targets? What will be the requirements for change in the energy system? If some countries act before others, how much will emissions "leak" from those that are acting to those that are not? How much flexibility is gained by allowing concentrations to temporarily overshoot long-term goals, and what are the other implications of overshoot pathways? These are important questions for negotiators working to craft global and regional climate architectures; and they will remain important questions well beyond current negotiations.

The EMF 22 International Scenarios are not the first effort to explore these three dimensions. They build on recent research that explores the implications of delayed participation in emissions mitigation (e.g., Bosetti et al., 2008; Edmonds et al., 2008; Richels et al., 2008) along with research exploring the implications of overshoot pathways toward concentration targets (e.g., den Elzen and van Vuuren, 2007; van Vuuren et al., 2007; Rao et al., 2008; Clarke et al., 2009). Whereas these previous studies were conducted independently, the EMF 22 International Scenarios provide a consistent multi-model approach to these issues.

The remainder of this paper proceeds as follows. Section 2 provides an overview of the design of the EMF 22 International Scenarios, including a discussion of ways to link key climate-related metrics such as concentrations, radiative forcing, and temperature. Section 3 identifies the scenarios that were produced for this study. Of particular interest are those situations in which modeling groups were not able to produce scenarios representing the more challenging cases. Section 4 discusses the emissions, concentrations, and temperature implications of the scenarios. Sections 5 and 6 discuss the energy system and economic results. Finally, Section 7 introduces other issues raised by individual papers in this volume, and Section 8 provides summary thoughts.

\section{Study design}

\subsection{Overview of the study design}

A total of ten climate-action cases were explored in these EMF 22 International Scenarios (Table 1), based on combinations of three different dimensions of mitigation:

- The long-term concentration target. Three long-term concentration targets for the Kyoto GHGs are explored: (1) 450 ppmv $\mathrm{CO}_{2}$-e [2.6 W/ $\left.\mathrm{m}^{2}\right]$, (2) $550 \mathrm{ppmv} \mathrm{CO}_{2}$-e $\left[3.7 \mathrm{~W} / \mathrm{m}^{2}\right]$, and (3) $650 \mathrm{ppmv} \mathrm{CO}_{2}$-e $\left[4.5 \mathrm{~W} / \mathrm{m}^{2}\right]$;

- The option to overshoot the long-term concentration target this century. Two options are explored: (1) a not-to-exceed formulation in which the long-term target cannot be exceeded at any point and (2) an overshoot formulation in which the long-term target must be met by 2100 , but in which concentrations can temporarily exceed the target prior to 2100 .

- The time-path of international participation in mitigation. Two assumptions regarding international participation in emissions reduction are explored: (1) full initial participation and (2) an architecture in which many-regions do not engage in climate mitigation until 2030 or beyond.

All modeling groups were required to attempt to produce scenarios representing each of these ten climate-action cases; however, as will

Table 1

The ten climate-action cases explored in the EMF 22 International Scenarios.

\begin{tabular}{llll}
\hline & & Full participation & Delayed participation \\
\hline $450 \mathrm{CO}_{2}$-e & Not-to-exceed & $\mathrm{X}$ & $\mathrm{X}$ \\
& Overshoot & $\mathrm{X}$ & $\mathrm{X}$ \\
\hline $550 \mathrm{CO}_{2}$-e & Not-to-exceed & $\mathrm{X}$ & $\mathrm{X}$ \\
& Overshoot & $\mathrm{X}$ & $\mathrm{X}$ \\
\hline \multirow{2}{*}{$650 \mathrm{CO}_{2}$-e } & Not-to-exceed & $\mathrm{X}$ & $\mathrm{X}$ \\
& Overshoot & Not modeled & Not modeled \\
& & &
\end{tabular}

be discussed in Section 3, no group succeeded in producing scenarios for all ten, and this result itself provides insight into the relative difficulty of the cases. In addition to the ten cases, all modeling groups were required to provide a reference, or no-climate-action, scenario as a point of departure for interpreting the climate-action scenarios.

With the exception of the three dimensions that define the climate-action cases, no attempt was made to standardize the models or scenarios. The variation in modeling approaches and assumptions is a defining characteristic of this study. The resulting differences across scenarios shed light on how key forces may evolve over time and the implications for meeting the three climate targets in this study under differing assumptions regarding overshoot and global participation.

\subsection{Participating models}

Ten models participated in the EMF 22 International Scenarios (Table 2). All participating models are global in scale and include submodels of the physical processes that convert global GHG emissions into global GHG concentrations. Some modeling groups attempted all or particular climate-action cases with multiple versions of their models, as shown in Table 2. Including all model versions, 14 models participated in the study. ${ }^{3}$ Table 2 also includes information on key supply technologies included in the scenarios, the time periods used to represent delayed participation, the model's intertemporal solution approach, and the papers in this volume associated with each model.

\subsection{The three long-term concentration targets and the link to temperature}

The three long-term climate-related targets explored in this study are defined in terms of the combined impact on the Earth's radiative balance of the primary anthropogenic GHGs: carbon dioxide $\left(\mathrm{CO}_{2}\right)$, nitrous oxide $\left(\mathrm{N}_{2} \mathrm{O}\right)$, methane $\left(\mathrm{CH}_{4}\right)$, hydrofluorocarbons (HFCs), perfluorocarbons (PFCs), and sulfur hexafluoride $\left(\mathrm{SF}_{6}\right)$. These gases are known as the Kyoto gases, because they form the basis for targets in the Kyoto Protocol. The Kyoto gases do not include other GHGs such as the Montreal Protocol gases or other radiatively-active substances such as aerosols.

Expressed in terms of radiative forcing (i.e., the impact on the Earth's radiative balance), the three concentration targets explored in this study are $2.6 \mathrm{~W} / \mathrm{m}^{2}, 3.7 \mathrm{~W} / \mathrm{m}^{2}$, and $4.5 \mathrm{~W} / \mathrm{m}^{2}$. These radiative forcing levels correspond to $\mathrm{CO}_{2}$-e concentrations of $450 \mathrm{ppmv} \mathrm{CO}_{2}$-e, $550 \mathrm{CO}_{2}$-e, and $650 \mathrm{CO}_{2}$-e. The concentration targets must be met in all scenarios by 2100 , which is the end of the study period. However, as we will discuss later in this section, one option is for scenarios to overshoot the target prior to 2100 .

The $\mathrm{CO}_{2}$-e concentration associated with the Kyoto gases is only one of several useful climate-related metrics. Table 3 provides a guide to the relationship between the Kyoto $\mathrm{CO}_{2}$-e concentrations and other important climate metrics.

The third column in Table 3 shows the $\mathrm{CO}_{2}$ concentrations in 2100 across all the scenarios that were submitted for this study. $\mathrm{CO}_{2}$ concentrations are lower than the associated $\mathrm{CO}_{2}$-e concentration targets, because $\mathrm{CO}_{2}$ is only one of the constituents of which the $\mathrm{CO}_{2}$-e concentrations are composed. For example, in the scenarios from this study, $450 \mathrm{ppmv} \mathrm{CO}_{2}$-e in 2100 corresponds to anywhere between 355 ppmv $\mathrm{CO}_{2}$ and 415 ppmv $\mathrm{CO}_{2}$ in 2100 . Hence, the $450 \mathrm{ppmv}$ $\mathrm{CO}_{2}$-e scenarios correspond to a future with $\mathrm{CO}_{2}$ concentration roughly at today's levels or below. It follows that, $450 \mathrm{ppmv} \mathrm{CO}_{2}$-e is a far more aggressive target than $450 \mathrm{ppmv} \mathrm{CO}_{2}$.

\footnotetext{
${ }^{3}$ In this paper, the term "model" is used to refer both to the ten models that were used in the study and the 14 individual versions of models that were submitted, including the multiple versions of specific models. As will be demonstrated throughout the paper, the variations in model versions for single models were often significant enough to result in very different scenarios.
} 
Table 2

Models participating in the EMF 22 International Scenarios.

\begin{tabular}{|c|c|c|c|c|c|c|c|c|c|c|}
\hline \multirow[t]{2}{*}{ Model } & \multirow[t]{2}{*}{$\begin{array}{l}\text { Origin of } \\
\text { Model }\end{array}$} & \multirow[t]{2}{*}{$\begin{array}{l}\text { Participating } \\
\text { Versions }\end{array}$} & \multicolumn{3}{|c|}{ Key supply technologies } & \multirow[t]{2}{*}{$\begin{array}{l}\text { Model time } \\
\text { step (years) }\end{array}$} & \multicolumn{2}{|c|}{$\begin{array}{l}\text { Last model year } \\
\text { with no GHG } \\
\text { price in delayed } \\
\text { participation } \\
\text { scenarios }\end{array}$} & \multirow[t]{2}{*}{$\begin{array}{l}\text { Intertemporal } \\
\text { solution approach }\end{array}$} & \multirow[t]{2}{*}{$\begin{array}{l}\text { Corresponding paper } \\
\text { in this volume }\end{array}$} \\
\hline & & & $\begin{array}{l}\text { New nuclear } \\
\text { energy }\end{array}$ & CCS & Bio w/CCS & & Group 2 & Group 3 & & \\
\hline ETSAP-TIAM & (Canada) & One Version & Yes & Yes & Yes & 10 & 2020 & 2040 & Intertemporal optimization & $\begin{array}{l}\text { Loulou et al. } \\
\text { (2009-this issue) }\end{array}$ \\
\hline FUND & (E.U) & One Version & \multicolumn{3}{|c|}{ No specific technologies } & 1 & 2029 & 2049 & Intertemporal optimization & Tol (2009-this issue) \\
\hline GTEM & (Australia) & One Version & Yes & Yes & No & 1 & 2029 & 2049 & Recursive dynamic & $\begin{array}{l}\text { Gurney et al. } \\
\text { (2009-this issue) }\end{array}$ \\
\hline IMAGE & (E.U.) & $\begin{array}{l}\text { IMAGE } \\
\text { IMAGE-BECS }\end{array}$ & $\begin{array}{l}\text { Yes } \\
\text { Yes }\end{array}$ & $\begin{array}{l}\text { Yes } \\
\text { Yes }\end{array}$ & $\begin{array}{l}\text { No } \\
\text { Yes }\end{array}$ & 1 & 2029 & 2049 & Recursive dynamic & $\begin{array}{l}\text { van Vliet et al. } \\
\text { (2009-this issue) }\end{array}$ \\
\hline MERGE & (U.S.) & $\begin{array}{l}\text { MERGE Optimistic } \\
\text { MERGE Pessimistic }\end{array}$ & $\begin{array}{l}\text { Yes } \\
\text { Yes }\end{array}$ & $\begin{array}{l}\text { Yes } \\
\text { Yes }\end{array}$ & $\begin{array}{l}\text { No } \\
\text { No }\end{array}$ & 10 & 2030 & 2050 & Intertemporal optimization & $\begin{array}{l}\text { Blanford et al. } \\
\text { (2009-this issue) }\end{array}$ \\
\hline MESSAGE & (E.U.) & $\begin{array}{l}\text { MESSAGE } \\
\text { MESSAGE-NoBECS }\end{array}$ & $\begin{array}{l}\text { Yes } \\
\text { Yes }\end{array}$ & $\begin{array}{l}\text { Yes } \\
\text { Yes }\end{array}$ & $\begin{array}{l}\text { Yes } \\
\text { No }\end{array}$ & 10 & 2030 & 2050 & $\begin{array}{l}\text { Intertemporal optimization } \\
\text { and dynamic recursive }\end{array}$ & $\begin{array}{l}\text { Krey and Riahi } \\
\text { (2009-this issue) }\end{array}$ \\
\hline MiniCAM & (U.S.) & $\begin{array}{l}\text { MiniCAM-Base } \\
\text { MiniCAM-LoTech }\end{array}$ & $\begin{array}{l}\text { Yes } \\
\text { Yes }\end{array}$ & $\begin{array}{l}\text { Yes } \\
\text { No }\end{array}$ & $\begin{array}{l}\text { Yes } \\
\text { No }\end{array}$ & 15 & 2035 & 2050 & Recursive dynamic & $\begin{array}{l}\text { Calvin et al. } \\
\text { (2009a-this issue) }\end{array}$ \\
\hline POLES & (E.U.) & One Version & Yes & Yes & Yes & 1 & 2030 & 2050 & Recursive dynamic & $\begin{array}{l}\text { Russ et al. } \\
\text { (2009-this issue) }\end{array}$ \\
\hline SGM & (U.S.) & One Version & Yes & Yes & No & 5 & 2026 & 2046 & Recursive dynamic & $\begin{array}{l}\text { Calvin et al. } \\
\text { (2009b-this issue) }\end{array}$ \\
\hline WITCH & (E.U.) & One Version & Yes & Yes & No & 5 & 2025 & 2045 & Intertemporal optimization & $\begin{array}{l}\text { Bosetti et al. } \\
\text { (2009-this issue) }\end{array}$ \\
\hline
\end{tabular}

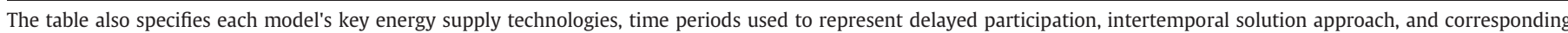
paper in this volume.

Table 3

Comparison of different metrics of climate change and GHG concentrations for the three Kyoto concentration targets in the EMF 22 International Scenarios.

\begin{tabular}{|c|c|c|c|c|c|c|c|}
\hline \multicolumn{2}{|c|}{2100 Targets: Kyoto gases only } & \multirow{3}{*}{$\begin{array}{l}\text { Results: } \mathrm{CO}_{2} \text {-only } \\
\text { [All participating models] } \\
\mathrm{CO}_{2} \text { concentration } \\
\text { in } 2100\end{array}$} & \multicolumn{2}{|c|}{$\begin{array}{l}\text { Results: Total forcing } \\
\text { (IPCC definition) } \\
\text { [from three participating models] }\end{array}$} & \multicolumn{3}{|c|}{$\begin{array}{l}\text { Results: Associated Equilibrium GMS } \\
\text { temperature change relative to preindustrial } \\
\text { [based on three participating models] }\end{array}$} \\
\hline $\begin{array}{l}\text { Radiative } \\
\text { forcing }\end{array}$ & $\begin{array}{l}\mathrm{CO}_{2} \text {-equivalent } \\
\text { concentration }\end{array}$ & & $\begin{array}{l}2100 \text { radiative } \\
\text { forcing }\end{array}$ & $\begin{array}{l}2100 \mathrm{CO}_{2} \text {-equivalent } \\
\text { concentration }\end{array}$ & Low & Medium & High \\
\hline & & & & & $(\mathrm{CS}=2)$ & $(\mathrm{CS}=3)$ & $(\mathrm{CS}=4.5)$ \\
\hline$\left(\mathrm{W} / \mathrm{m}^{2}\right)$ & (ppmv) & (ppmv) & $\left(\mathrm{W} / \mathrm{m}^{2}\right)$ & (ppmv) & $\left({ }^{\circ} \mathrm{C}\right)$ & $\left({ }^{\circ} \mathrm{C}\right)$ & $\left({ }^{\circ} \mathrm{C}\right)$ \\
\hline 2.6 & 450 & $355-415$ & $23-2.7$ & $427-460$ & $1.2-1.5$ & $1.9-2.2$ & $2.8-3.3$ \\
\hline 3.7 & 550 & $425-484$ & $3.5-3.8$ & $535-566$ & $1.9-2.1$ & $2.8-3.1$ & $4.3-4.6$ \\
\hline 4.5 & 650 & $501-545$ & $4.2-4.5$ & $610-645$ & $2.3-2.4$ & $3.4-3.6$ & $5.1-5.5$ \\
\hline
\end{tabular}

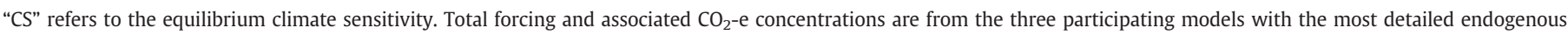

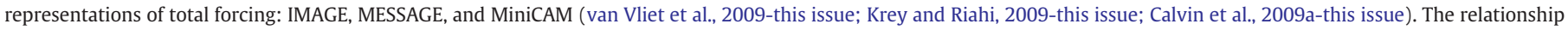
between equilibrium temperature and total forcing is based on Meehl et al. (2007, Section 10.7 and Table 10.8).

The fourth and fifth columns in Table 3 show the range of total forcing (as opposed to Kyoto forcing) in 2100 from the three participating models with the most detailed endogenous representations of the nonKyoto emissions that determine total forcing (IMAGE, MESSAGE, and MiniCAM). ${ }^{4}$ Total forcing includes the impact of additional substances and factors, beyond the Kyoto gases, that affect the Earth's radiative balance such as the Montreal gases, tropospheric and stratospheric ozone, surface albedo change and, in particular, aerosols - mostly

\footnotetext{
${ }^{4}$ IMAGE, MESSAGE, and MiniCAM are three of the four models producing Representative Concentration Pathways (RCPs) process through the Integrated Assessment Modeling Consortium (IAMC). The fourth model is AIM. The RCPs are part of a process in which climate and IA modelers will work in parallel toward the generation of new integrated scenarios of climate change to support the IPCC's Fifth Assessment Report. The selection of the four RCP models is documented in Moss et al. (2008).
}

sulfate, black carbon, and organic carbon. Total forcing is a more complete representation of the full anthropogenic effect on the Earth's radiative balance than Kyoto forcing, and therefore a better indicator of potential climate change.

Across the three targets, total forcing from the three models converges to a level close to Kyoto-only forcing by 2100 . This convergence represents a marked change from the present. As of 2005 , total forcing was roughly $1.6 \mathrm{~W} / \mathrm{m}^{2}$ or about $375 \mathrm{ppmv} \mathrm{CO}_{2}$-e (Forster et al., 2007), and Kyoto-only forcing was roughly $2.3 \mathrm{~W} / \mathrm{m}^{2}$ or $430 \mathrm{ppmv} \mathrm{CO}_{2}$-e. A full discussion of the reasons for this convergence and the implications for meeting particular climate-action cases is provided in Section 4.3. Here we note only that the convergence between these metrics means that, over the long-term, Kyoto-only forcing is roughly consistent with total forcing.

The final two columns of Table 3 show the long-term equilibrium temperature increase that would result if global Kyoto concentrations were to be held over the long-term at the targets in this study. $\mathrm{A} 2{ }^{\circ} \mathrm{C}$ long- 
term target can only be reached at a climate sensitivity ${ }^{5}$ of $3{ }^{\circ} \mathrm{C}$ if concentrations are stabilized over the long-term at 450 ppmv $\mathrm{CO}_{2}$-e or below. The Intergovernmental Panel on Climate Change (IPCC) argues that $3{ }^{\circ} \mathrm{C}$ is the most likely climate sensitivity, and that climate sensitivity lies in the interval of $2{ }^{\circ} \mathrm{C}$ to $4.5^{\circ} \mathrm{C}$ with a probability of greater than $66 \%$ (Meehl et al., 2007). Research has indicated enormous uncertainty in climate sensitivity. Some estimates have put the $90 \%$ confidence interval at between $1{ }^{\circ} \mathrm{C}$ and over $9{ }^{\circ} \mathrm{C}$ (Meehl et al., 2007). A $2{ }^{\circ} \mathrm{C}$ long-term target can only be reached with a long-term concentration of $550 \mathrm{ppmv} \mathrm{CO}_{2}$-e if the climate sensitivity is at the low end of the IPCC range (climate sensitivity of $2{ }^{\circ} \mathrm{C}$ ).

The relationship between the Kyoto-only $\mathrm{CO}_{2}$-e concentration targets and temperature increase needs to be qualified in three important ways. First, the actual, or transient, temperature lags the equilibrium temperature due to the long time scale of the ocean temperature response to changing atmospheric concentrations. The transient temperature increase may lag the equilibrium temperature by $0.5^{\circ} \mathrm{C}$ or more depending on the scenario, and convergence between the two may take many centuries. Hence, it is possible to keep the temperature increase below, say, a $2{ }^{\circ} \mathrm{C}$ target while still temporarily exceeding the corresponding equilibrium $\mathrm{CO}_{2}$-e concentration. Second, the EMF 22 International Scenarios only consider the period up to 2100 . Concentrations could increase or decrease after 2100 depending on mitigation efforts beyond 2100 . Finally, in the overshoot scenarios, it is possible for temperatures to exceed the longterm equilibrium level prior to 2100 if concentrations exceed the longterm targets for a sufficient period over the century. The temperature implications of the scenarios are discussed in more detail in Section 4.3.

\subsection{Overshoot and not-to-exceed scenarios}

The second dimension by which the climate-action cases are differentiated is whether the concentration target can be exceeded in this century. Recall that the concentration targets must be met in 2100. There are two formulations used in this study. In the not-toexceed formulation, the concentration target cannot be exceeded prior to 2100. In, contrast, in the overshoot formulation, concentrations can exceed the 2100 target at any time during the century as long as the target is met in 2100. This overshoot option provides greater near-term flexibility to meet targets. However, if overshoot occurs, it requires greater action later in the century than a not-toexceed formulation, and it is possible that temperatures could exceed those associated with long-term equilibrium levels prior to 2100 .

\subsection{Degrees of international participation in climate mitigation}

The degree and nature of near-term international action on mitigation is at the core of the EMF 22 International Scenarios. Two possible international policy architectures are explored in this study. The full participation architecture assumes that all countries begin emissions reductions, in a coordinated fashion, in 2012 and that mitigation is undertaken where it is least costly; that is, the marginal costs of abatement are equalized across regions. The full participation formulation is an idealized best-case that, although unrealistic, provides a useful benchmark for understanding the influence of less-than-comprehensive climate action. It provides a floor on total global mitigation costs.

A more realistic future than the full participation formulation is that countries will take on differentiated responsibilities, with some regions, most likely the developed regions, taking on more mitigation initially than other regions. Hence, the EMF 22 International Scenarios also explore a delayed participation scenario in which the majority of the developed regions begin mitigation as a group in 2012 (Group 1) and the remaining regions (Group 2 and Group 3 ) enter at different points in the future (Fig. 1). To be clear, the formulation of delayed participation in this study is a single, representative case intended to

\footnotetext{
${ }^{5}$ The climate sensitivity characterizes the global mean equilibrium temperature response to a doubling of $\mathrm{CO}_{2}$-e concentrations.
}

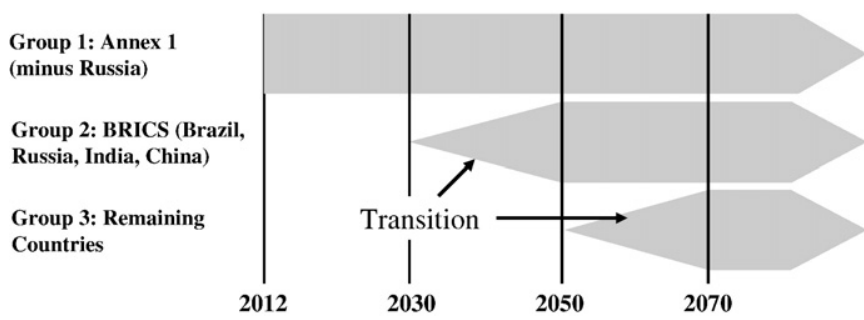

Fig. 1. The delayed participation architecture explored in EMF 22 International Scenarios.

gain insights into the effects of delayed participation. It is not intended to mirror specific real-world policy proposals, which may, for example, be based not on the absence of action in Groups 2 and 3, but on differentiated levels of action among regions and countries.

Group 1 includes the Annex 1 countries minus Russia; this roughly corresponds to the OECD. This group begins mitigation in 2012 and serves as the initial coalition for action on climate. It is assumed that all countries in this coalition see the same price on carbon so that marginal costs are equalized across countries in the coalition. This could be achieved through a carbon tax or a tradable permit scheme. The precise mechanism is left unspecified.

Group 2 consists of Brazil, Russia, India, and China (or BRICs). Group 2 begins mitigation in 2030. Group 2 does not begin mitigation at the going carbon price in Group 1, but instead begins at a lower price which rises gradually over 20 years until, in 2050, Group 2 is at the same price level as Group 1. Group 2's initial carbon price (in 2030) is set equal to Group 1's 2012 price; that is, Group 2 enters under the same conditions as Group 1. Group 3, consisting of the remaining Non-Annex 1 countries, enters in 2050, again at Group 1's initial price, which, as with Group 2, gradually rises to the Group 1 and Group 2 price by 2070 .

The specification of the delayed participation formulation was broad enough to allow for some differences in interpretation by the modeling teams, and these differences in interpretation led to differences in model behavior. First, modeling groups differed mechanically in terms of the precise model periods in which Group 2 and Group 3 experienced their first carbon price. For example, many of the models interpreted the 2030 entry date for Group 2 (BRICs) to mean that the initial carbon price should be applied to Group 2 in the 2030 model period. In contrast, other modelers chose to employ a zero carbon price in the 2030 model period and to apply the initial carbon price in the following model period. This means that the onset of mitigation in one set of models was one model period earlier than in the other set. Table 2 provides information on the last model periods in which Group 2 and Group 3 did not experience a carbon price.

A second difference in the interpretation of the delayed participation regime is that many of the models did not include definitions of world regions that exactly matched the regional definitions in the delayed participation formulation. For example, many models do not have Brazil or Russia as separate regions. These models might, for example, use Latin America to represent Brazil or the former Soviet Union to represent Russia. Or they might include Brazil in Group 3 instead of Group 2. The use of regional structures that differ from the precise regional definitions for this study could make the delayed participation scenarios more or less difficult than they would if precise regional representations were possible, depending on whether mitigation for particular countries is pushed backward or forward in time. However, given that most models have effective coverage of the Annex 1 regions, Russia, India, and China, this difference between study and model regions did not create large differences in the implications of the scenarios across models.

Finally, the delayed participation formulation requires that no mitigation be taken prior to accession, even in anticipation of later action. Many of the models participating in this study are intertemporally optimizing models, meaning that these models endogenously allocate emissions reductions over time in a way that would be most economically efficient. In these models, non-participating regions would otherwise 
Table 4

The scenarios submitted by the participating modeling teams.

\begin{tabular}{|c|c|c|c|c|c|c|c|c|c|c|c|}
\hline \multirow{2}{*}{\multicolumn{2}{|c|}{ Model }} & \multicolumn{2}{|c|}{650 CO2-e } & \multicolumn{4}{|c|}{550 CO2-e } & \multicolumn{4}{|c|}{450 CO2-e } \\
\hline & & $\begin{array}{l}\text { Full } \\
\text { Not-to- } \\
\text { exceed }\end{array}$ & $\begin{array}{l}\text { Delay } \\
\text { Not-to- } \\
\text { exceed }\end{array}$ & \multicolumn{2}{|c|}{ Full } & \multicolumn{2}{|c|}{ Delay } & \multicolumn{2}{|c|}{ Full } & \multicolumn{2}{|c|}{ Delay } \\
\hline 2 & FUND & + & + & + & + & + & + & + & $\mathrm{X}$ & $\mathrm{x}$ & $\mathrm{X}$ \\
\hline 3 & GTEM & + & + & + & + & + & $\mathrm{x}$ & + & $\mathrm{X}$ & $\mathrm{x}$ & $\mathrm{x}$ \\
\hline 4 & IMAGE & + & + & + & + & + & + & $\mathrm{x}$ & $\mathrm{x}$ & $\mathrm{x}$ & $\mathrm{x}$ \\
\hline \multirow{2}{*}{5} & MERGE Optimistic & + & + & + & + & $\mathrm{x}$ & $\mathrm{x}$ & $\mathrm{x}$ & $\mathrm{x}$ & $\mathrm{x}$ & $\mathrm{x}$ \\
\hline & MERGE Pessimistic & + & + & + & + & + & + & $\mathrm{x}$ & $\mathrm{x}$ & $\mathrm{x}$ & $\mathrm{x}$ \\
\hline \multirow{2}{*}{6} & MESSAGE & + & + & + & + & + & $\mathrm{x}$ & + & $\mathrm{x}$ & $\mathrm{x}$ & $\mathrm{x}$ \\
\hline & MESSAGE-NoBECS & + & $\mathrm{N} / \mathrm{A}$ & + & + & $\mathrm{N} / \mathrm{A}$ & $\mathrm{N} / \mathrm{A}$ & + & $\mathrm{x}$ & $\mathrm{x}$ & $\mathrm{x}$ \\
\hline 7 & MiniCAM-Base & + & + & + & + & + & $\mathrm{X}$ & + & + & + & $\mathrm{x}$ \\
\hline
\end{tabular}

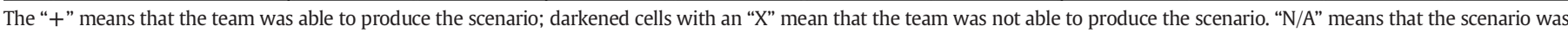
not attempted with the given model or model version.

normally anticipate later participation and make appropriate investments in non-emitting capital prior to accession, leading to early mitigation. Because the formulation specifically called for no mitigation prior to accession, many of these modelers simply held non-participating region emissions at their reference scenario value. This approach limits the opportunities to explore emissions leakage. On the other hand, if fully implemented, the intertemporal solution approach can be used to explore the implications of countries' anticipation of future climate agreements. Several models explored this issue through sensitivity analysis from the core climate-action cases (Blanford et al., 2009-this issue; Bosetti et al., 2009-this issue), and these are discussed in more detail in Section 6.3.

Two final points should be kept in mind in interpreting the delayed participation architecture in this study. First, although the delayed participation architecture introduces substantial inefficiencies through the delayed mitigation of many countries, it assumes cost-effective mitigation in those countries that are part of the coalition. Real-world policies may include inefficiencies even within coalitions of participating countries. Second, it should be emphasized that the delayed participation formulation eventually becomes a full-participation scenario - by 2070 . The difference between the two international architectures in the EMF 22 International Scenarios is the time until full participation is achieved. Ultimately, full participation is necessary to stabilize GHG concentrations.

\section{Study results: an overview of the scenarios}

All modeling teams participating in the EMF 22 International Scenarios were required to attempt to produce scenarios for all ten climate-action cases. However, no team succeeded in producing scenarios for all ten. Modelers were instructed that they were not required to submit scenarios representing particular climate-action cases if at least one of the following conditions was met:

- Physical infeasibility: The climate-action case was physically infeasible according to the model because the radiative forcing target was exceeded prior to the initiation of mitigation in Group 2 (BRICs) and Group 3 (the Non-Annex 1 countries).

- Model solution: The model could not be solved for the particular climate-action case, which could be due to failures in the solution mechanism at higher $\mathrm{CO}_{2}$ prices, decline or expansion constraints that hold back the rate of change in key sectors such as energy, or $\mathrm{CO}_{2}$ price limits in model.
- High initial price: Modelers were requested not to produce scenarios if the initial carbon price in Group 1 exceeded $\$ 1000 / \mathrm{tCO}_{2}$ in 2012.

Table 4 shows the scenarios produced for this study. Unfortunately, methodological issues prevented precise identification of the obstacles to producing particular scenarios. For example, if modelers chose to stop searching for the solution to a particular climate-action case because the initial carbon price exceeded the threshold, the case may ultimately have been physically infeasible or the model may not have been able to find a solution.

Nonetheless, it is possible to draw some conclusions regarding the reasons that particular cases were not produced. First, physical infeasibility was only applicable to not-to-exceed scenarios. To take an extreme example, the flexibility provided by the option to overshoot would generally allow targets to be met by 2100 if all emissions were eliminated from regions immediately after they began taking on emissions reductions. Further, with the possible exception of the not-to-exceed 450 ppmv $\mathrm{CO}_{2}$-e target, physical infeasibility was relevant only to delayed participation climate-action cases.

In general, Table 4 confirms expectations about the difficulty of particular targets. The difficulty increases as the constraint is tightened, as the globe deviates from full participation, and as the ability to overshoot targets is restricted. More specifically, delayed participation

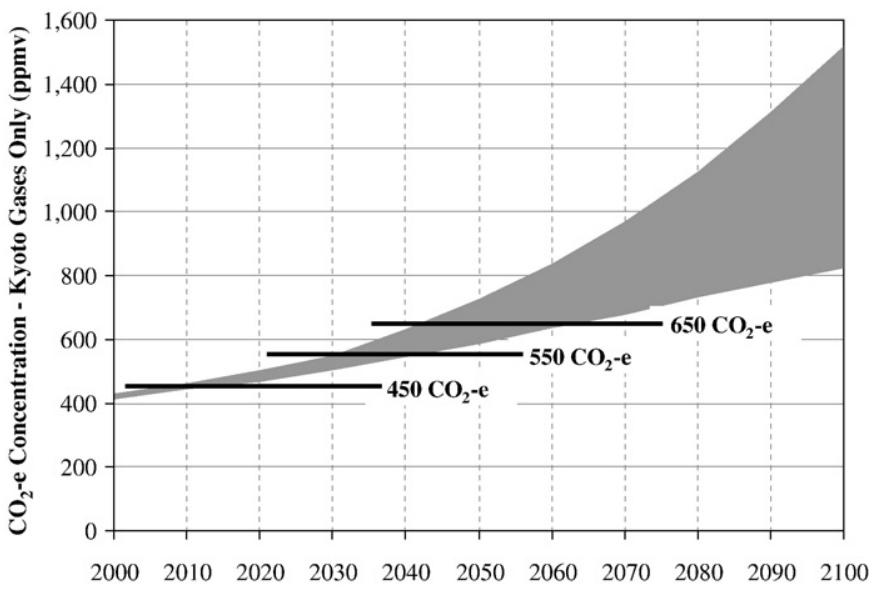

Fig. 2. $\mathrm{CO}_{2}$-e concentrations of the Kyoto gases across the EMF 22 reference scenarios 


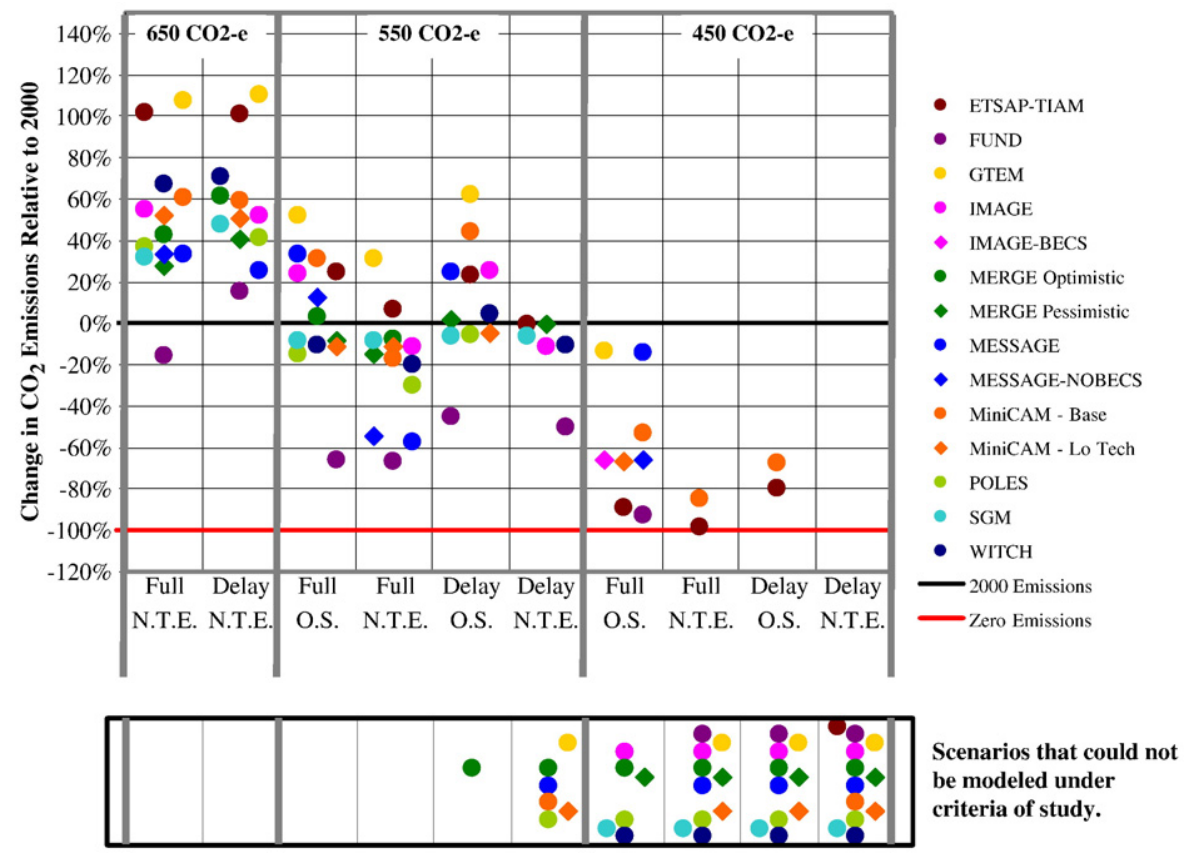

Fig. 3. Global emissions from fossil and industrial sources in 2050 across scenarios participating in this study.

could make $450 \mathrm{CO}_{2}$-e targets, and perhaps even $550 \mathrm{CO}_{2}$-e targets, physically infeasible if concentrations are not allowed to temporarily exceed their long-term targets.

The $\mathrm{CO}_{2}$-e concentrations emerging from the reference scenarios (Fig. 2) provide insight into the relative challenges of the climate-action cases. In all the reference scenarios, the 450 ppmv $\mathrm{CO}_{2}$-e target was exceeded within a decade (i.e., prior to 2020). The associated stringency was the reason that no model was able to produce the not-to-exceed 450 ppmv $\mathrm{CO}_{2}$-e case with delayed participation. On the other hand,

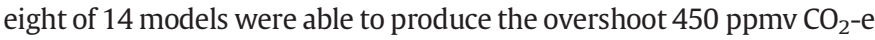
case with full participation.

The availability of bioenergy coupled with CCS (bioCCS) had an influence on which models could represent this case (compare Tables 2 and 4), as did other factors, such as reference case emissions levels. Only one model with bioCCS was unable to represent the overshoot 450 ppmv $\mathrm{CO}_{2}$-e case with full participation. At the same time, a number of models without bioCCS were able to produce this case, reinforcing the notion that the negative emissions from bioCCS are not the only means to meet overshoot targets. Only two models were able to produce the remaining 450 ppmv $\mathrm{CO}_{2}$-e cases: not-toexceed with full participation and overshoot with delayed participation. Both of these models included the option for bioCCS.

It is important to note that the not-to-exceed formulation for the 450 ppmv $\mathrm{CO}_{2}$-e scenarios could have different characteristics if the target were based on total radiative forcing rather than Kyoto-only radiative forcing. Because total forcing is noticeably lower than Kyotoonly forcing today, there is potentially greater head room to meet not-toexceed targets. However, because this head room is largely the result of negative forcing from aerosol emissions, which are coincident with fossil fuel combustion (they are also associated with other environmental problems), $\mathrm{CO}_{2}$ abatement would result in decreased aerosol emissions. The reduction would bring Kyoto and total forcing closer together. The effect of the additional head room on meeting tight, not-to-exceed targets is therefore ambiguous.

The 550 ppmv $\mathrm{CO}_{2}$-e climate action cases are, not surprisingly, easier for the models to represent with the exception of the not-to-exceed scenario with delayed participation. This is consistent with reference emissions across models exceeding 550 ppmv $\mathrm{CO}_{2}$-e between 2030 and 2045. The concentration target is tight enough that delays of the sort explored in this study would make it difficult to stay below it. Finally, all models were able to represent the $650 \mathrm{ppmv} \mathrm{CO}_{2}$-e climate action scenarios. Reference concentrations do not exceed 650 ppmv $\mathrm{CO}_{2}$-e until around mid-century, leaving a great deal of flexibility to meet this target, even with delays by the developing regions.

The inability of a particular model to produce a scenario does not necessarily mean that the scenario is infeasible. Model solution issues and high initial carbon prices in particular are a function of the assumptions of the model. For example, modeling groups who assumed more aggressive technology options (e.g., cheaper energy technologies, the option for bioCCS) found lower carbon prices and less pressure on the solution mechanisms of the models. Where climate-action cases could not be modeled solely for model solution or high initial price reasons, this is an indication of particularly high rates of change in the energy and other climate-related sectors, which may prove politically difficult to produce, but does not imply a lack of physical feasibility. Climate-action cases that were not modeled due to physical infeasibility - the radiative forcing target was exceeded prior to the onset of mitigation by all of the world's regions - make a stronger statement about the challenge of these particular climate-action cases. However, even here, modeling assumptions, particularly those concerning emissions growth in Groups 2 and 3, were partially responsible for the outcome. Not surprisingly, models that assumed greater growth in these regions or models that delayed participation longer had a lower chance of meeting a given target.

\section{Emissions, concentrations, and temperature across the scenarios}

\subsection{Global emissions}

Fig. 3 shows the change in global $\mathrm{CO}_{2}$ (not $\mathrm{CO}_{2}$-e) emissions relative to 2000 in 2050 across all the EMF 22 International Scenarios. Note that the figure also shows which scenarios were attempted but not completed for each climate-action case. Consistent with intuition, the reductions increase with the stringency of the target. Delay has a limited impact on global emissions, but generally leads to slightly higher global emissions in 2050 relative to similar cases without delay. ${ }^{6}$ (The impact on regional emissions is discussed in Section 4.2.)

\footnotetext{
${ }^{6}$ Note that this result is also a function of differences in the approach to the allocation of emissions across regions and over time in the delayed participation climate-action cases. Several modeling groups used identical global pathways with full and delayed participation.
} 
Overshoot has a more ambiguous effect on 2050 emissions but generally increases emissions in 2050 relative to similar scenarios under a not-to-exceed formulation. It is important to note, however, that less aggressive reductions up to 2050 resulting from delayed participation and from overshoot lead to greater reductions beyond 2050. We return to this point later.

One reason for the range in global reductions among models for any climate-action case is land use uptake or emissions. The FUND scenarios include a terrestrial biosphere feedback that increases terrestrial emissions as concentrations increase. For example, in the not-to-exceed $650 \mathrm{ppmv} \mathrm{CO}_{2}$-e scenario with full participation, global industrial emissions are $22 \mathrm{GtCO}_{2}$ in 2050 with the feedback; without the feedback, emissions are $38 \mathrm{GtCO}_{2}$. That is, the feedback forces a further emissions reduction of $16 \mathrm{GtCO}_{2}$ (Tol, 2009-this issue). To meet any given target, lower fossil and industrial emissions are required in the presence of the feedback. In contrast, the GTEM scenario assumes land use uptake that ranges from $2 \mathrm{GtCO}_{2} / \mathrm{yr}$ to more than $7 \mathrm{GtCO}_{2} / \mathrm{yr}$ (Gurney et al., 2009-this issue). Hence, the fossil and industrial emissions from FUND tend to be on the low side of the range across scenarios and those from GTEM tend to be on the high side.

A second factor is variation in the degree to which long-term targets are temporarily exceeded in those scenarios that allow for overshoot. As an example, Fig. 4 shows the emissions and $\mathrm{CO}_{2}$-e concentration pathways in the 450 ppmv $\mathrm{CO}_{2}$-e scenarios. Although the long-term target is 450 ppmv $\mathrm{CO}_{2}$-e, concentrations in five of the models exceed $500 \mathrm{ppmv} \mathrm{CO}_{2}$-e prior to 2100 . Because these scenarios allow for greater overshoot, they tend to have higher emissions in 2050 than those scenarios with less aggressive overshoot.

Negative fossil and industrial emissions through the use of bioCCS technology are not required for overshoot pathways. Overshoot can be achieved without negative emissions by taking advantage of the delays in the carbon cycle; that is, the physical process for removing $\mathrm{CO}_{2}$ from the atmosphere. For example the MESSAGE-NoBECS scenario still overshoots the long-term target significantly in Fig. 4. To achieve this degree of overshoot, however, fossil and industrial emissions must be reduced far more substantially in the near term than if bioCCS were available to bring emissions below zero in the second half of the century.
The overshoot scenarios are something of a conundrum for negotiators and policy makers (Kheshgi et al., 2005; Wigley et al., 2007; den Elzen and van Vuuren, 2007; Clarke et al., 2009). On the one hand, they allow for greater flexibility to gradually reduce emissions over the coming decades while still allowing the world to reach more aggressive climate-related targets in the long run. Indeed, the notion of overshoot raises the possibility that concentrations could continue falling beyond 2100 if the world continues abatement into the next century. On the other hand, overshoot scenarios raise some very serious concerns. Taking advantage of near-term flexibility requires more aggressive action in the second-half of the century. Indeed, the scenarios that take greatest advantage of overshoot have the lowest emissions in the second-half of the century; and some of these scenarios are based on negative global emissions beyond 2050 through extensive use of biocCS. If policy makers commit to aggressive climate-related targets based on overshoot pathways, they can relax actions today, but they are depending on potentially very aggressive measures in the second-half of the century measures that need to be implemented long after many of these policy makers have left office.

In addition, overshoot scenarios can lead to larger near-term changes in climate than not-to-exceed scenarios. Note that the highend of the range of mid-century GHG concentrations in the overshoot 450 ppmv $\mathrm{CO}_{2}$-e full participation scenarios reaches almost $600 \mathrm{ppmv}$ $\mathrm{CO}_{2}$-e in 2050, and there are four scenarios in which concentrations exceed 500 ppmv $\mathrm{CO}_{2}$-e in 2050. The temperature implications of overshoot are discussed in more detail in Section 4.3. Here we note only that given the thermal lags in the climate system, the increase in temperature remains below $2{ }^{\circ} \mathrm{C}$ this century in all but one of the 450 ppmv $\mathrm{CO}_{2}$-e overshoot scenarios, assuming the IPCC's most likely climate sensitivity of $3{ }^{\circ} \mathrm{C}$.

Referring back to Fig. 3, the difficulty of achieving 450 ppmv $\mathrm{CO}_{2}-\mathrm{e}$ is evident from the emissions reductions in 2050. In the most flexible scenario - full participation with overshoot - only 8 of the fourteen models that attempted the scenario were able to complete the scenario under the requirements of the study. In addition, if the GTEM scenario (which includes the greatest terrestrial uptake and the

\section{Global $\mathrm{CO}_{2}$ Emissions}

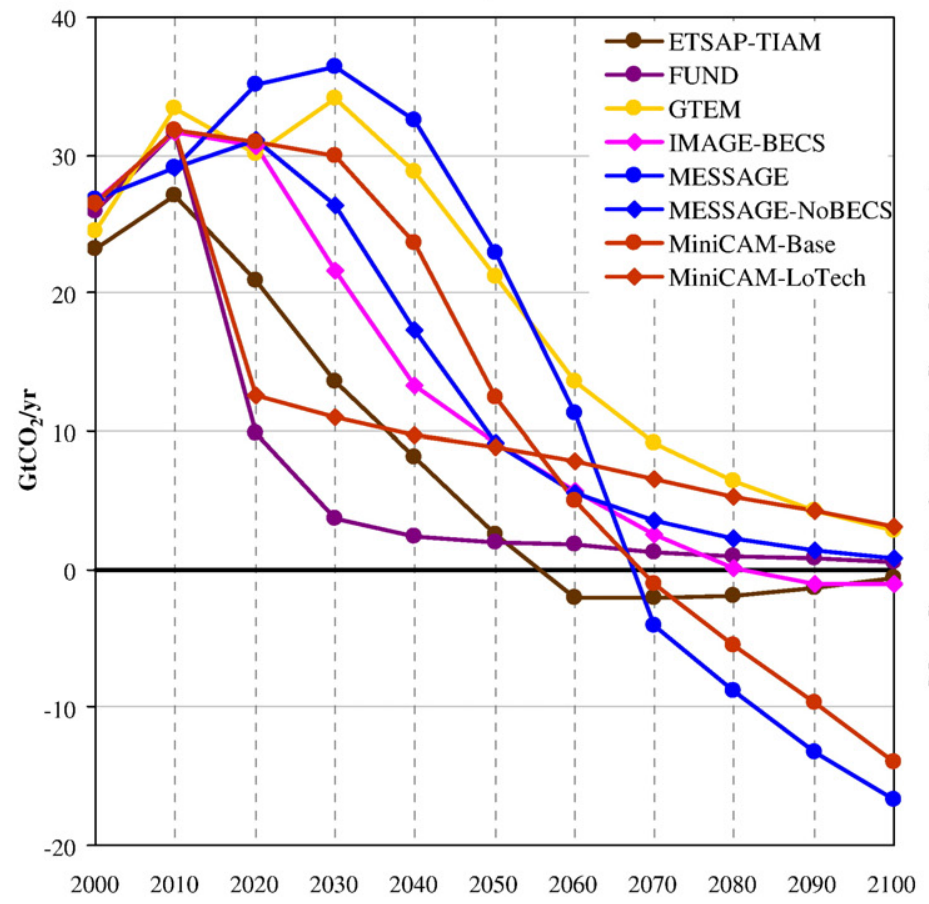

Global $\mathrm{CO}_{2}$-e Concentrations

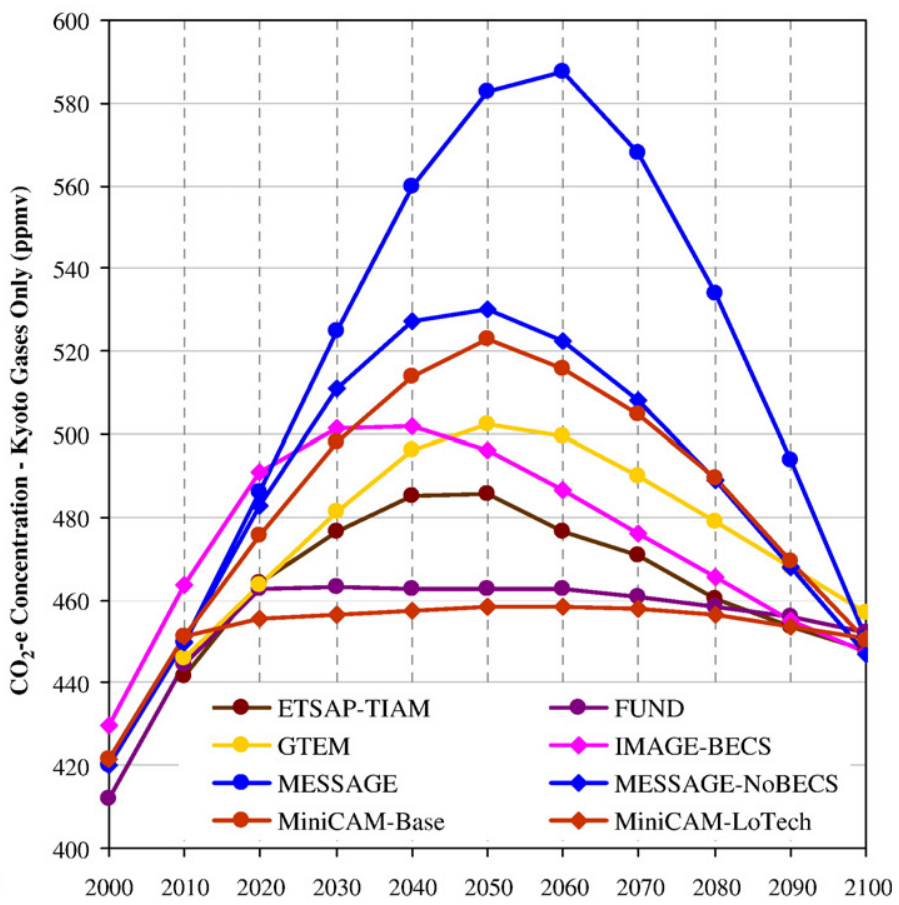

Fig. 4. Global $\mathrm{CO}_{2}$ emissions and $\mathrm{CO}_{2}$-e concentrations in the overshoot $450 \mathrm{CO}_{2}$-e scenarios with full participation. 

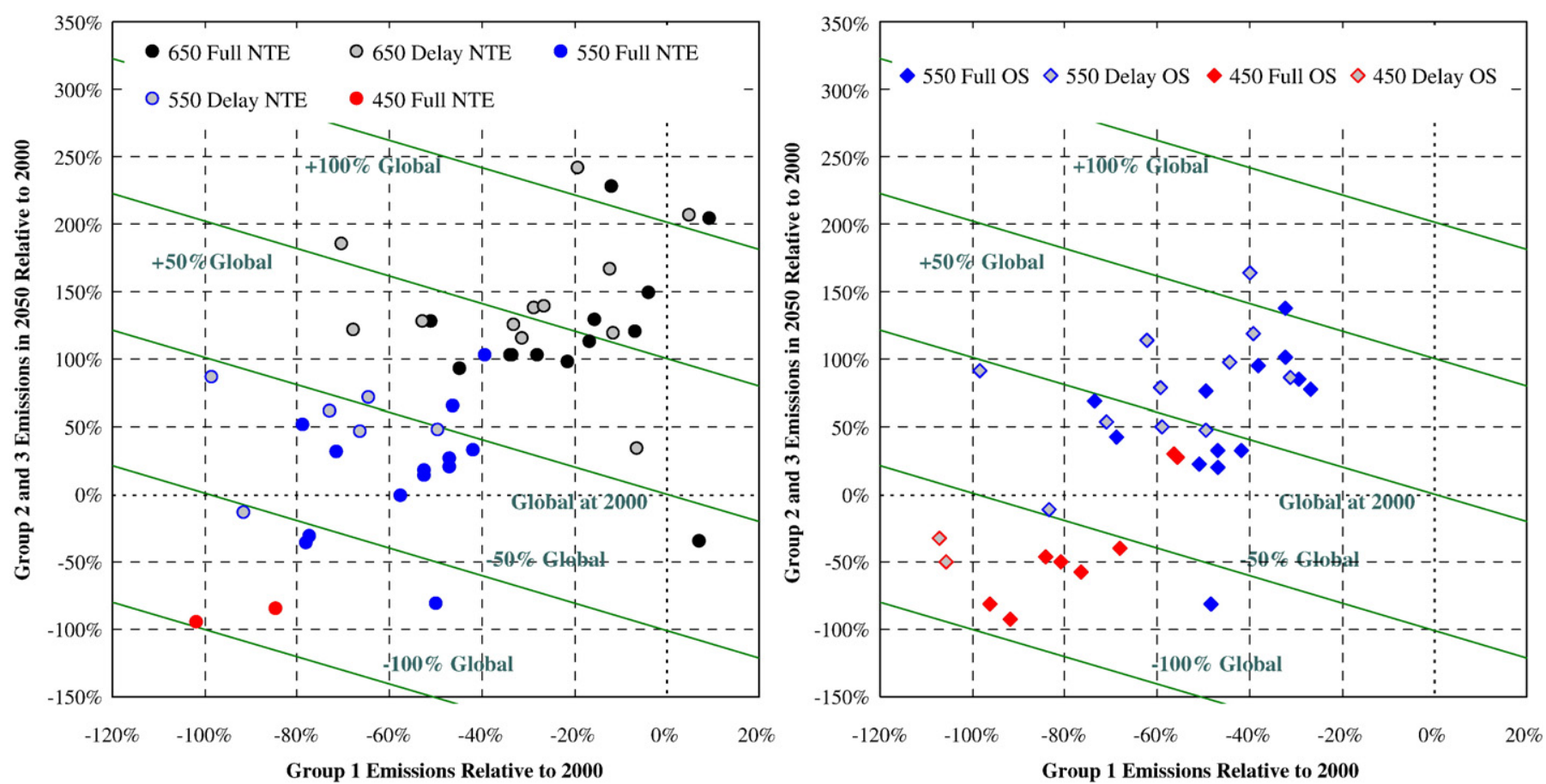

Fig. 5. Group $2+3$ emissions plotted against Group 1 emissions in 2050 across the not-to-exceed scenarios (left panel) and the overshoot scenarios (right panel).

highest reference emissions growth) and the MESSAGE scenario (which includes the most aggressive negative emissions in the second half of the century) are excluded from the discussion, then global emissions reductions in 2050 relative to 2000 range from $60 \%$ to almost $100 \%$. Global emissions reductions were more than $60 \%$ in both models that were able to produce the overshoot $450 \mathrm{ppmv} \mathrm{CO}_{2}$-e specification with delayed participation; and reductions were almost $100 \%$ below 2000 levels for the not-to-exceed 450 ppmv $\mathrm{CO}_{2}$-e scenario with full participation. In contrast, emissions in the 550 ppmv $\mathrm{CO}_{2}$-e scenarios, although varying across scenarios and models, roughly cluster around or slightly below 2000 emissions levels. The $650 \mathrm{ppmv} \mathrm{CO}_{2}$-e scenarios generally allow for robust increases in global emissions up to 2050.

\subsection{The distribution of emissions reductions across regions}

Fig. 5 shows global the distribution of emissions reductions across study regions in 2050 and across scenarios. Groups 2 and 3 are combined in the figure to represent the non-Annex 1 regions plus Russia; Group 1 represents the Annex 1 regions absent Russia. The left panel of Fig. 6 shows emissions combinations from not-to-exceed scenarios, and the right panel shows emissions combinations for overshoot cases.

The scatter of emissions mitigation combinations tends to slope from upper right to lower left as the concentration target becomes more stringent, a reflection of the fact that emissions decline for all groups as the constraint becomes more stringent. The 450 ppmv $\mathrm{CO}_{2}$-e scenarios are in the lower left corner of the figure, and the $550 \mathrm{ppmv}$ $\mathrm{CO}_{2}$-e and 650 ppmv $\mathrm{CO}_{2}$-e scenarios are distributed upward and to the right. There is a clear increase in emissions in the overshoot cases relative to the not-to-exceed cases, as overshoot allows increased emissions prior to the end of the century.

Fig. 5 also contains information about combinations of emissions between Group 1 and Groups 2 and 3 which are equivalent - the green "iso-global-emissions" lines. These lines slope from upper left to lower right, reflecting the fact that as emissions in Group 1 increase, emissions in the sum of Groups 2 and 3 must decrease to keep total global emissions constant. In general, the delayed participation does not dramatically alter global emissions in 2050. Instead, delay causes a shift in the distribution of emissions among regions in 2050, an upward and leftward shift along the constant global emissions lines in Fig. 5 . $^{7}$

This zero-sum character of the 2050 reductions has important implications for the use of international offsets to meet domestic emissions targets. If the developed countries purchase international offsets from the developing countries in order to lessen the actual physical mitigation requirement in the developed countries, then more total emissions reduction must be undertaken in the developing regions to meet that same long-term target. In other words, the reductions that one country pays for, through its own mitigation and through purchases of offsets in other regions, cannot be confused with the actual physical reductions in that country.

As an example, let us consider the not-to-exceed 550 ppmv $\mathrm{CO}_{2}$-e scenarios. In general, these scenarios cluster around roughly 2000level emissions in 2050 to a $50 \%$ decrease below 2000 levels. Let us consider the case of a $25 \%$ decrease below 2000 levels. If Group 1 were to undertake an $80 \%$ reduction below 2000 levels, then Group 2 and 3 together would be able to increase emissions to roughly $30 \%$ above 2000 levels. If, on the other hand, through international offsets, Group 1 were to purchase emissions reductions in Group 2 and Group 3 and to only undertake roughly $40 \%$ reductions domestically, then Groups 2 and 3 would, together, need to reduce emissions to about $10 \%$ below 2000 levels in 2050.

\subsection{The full-forcing and temperature implications of the scenarios}

Temperature has become a common currency for conversation regarding long-term climate-related goals. It is therefore useful to roughly outline the relationship between the scenarios in this study, which were constructed based on Kyoto-only forcing metrics, and temperature change. Because the study did not specifically address temperature and temperature goals, it did not produce a highly robust set of analyses for exploring temperature. Nonetheless, many of the

\footnotetext{
7 See footnote 6 .
} 

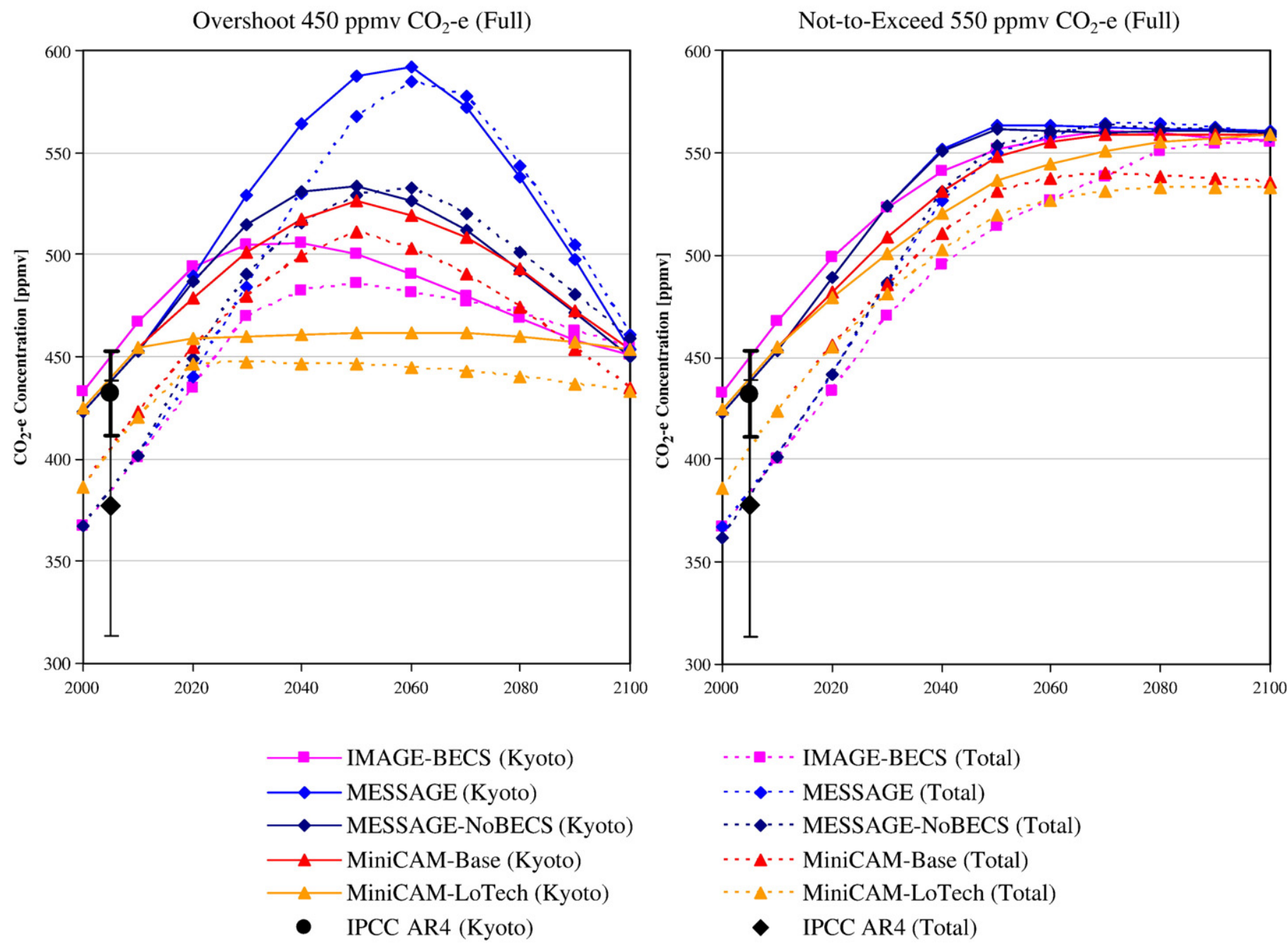

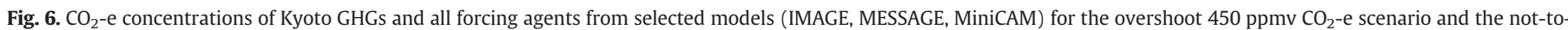

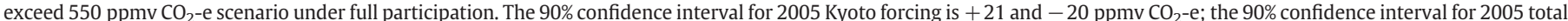
forcing is +61 and -64 ppmv $\mathrm{CO}_{2}$-e (Forster et al. 2007).

models in the study are capable of commenting on the full-gas forcing and temperature implications of the scenarios, and several salient observations emerge from this work. Here we briefly highlight three observations from a review of a subset of the models participating in the study. The models chosen for this comparison - IMAGE, MESSAGE, and MiniCAM - have the most detailed endogenous representations of the non-Kyoto emissions that determine total forcing. ${ }^{8}$

First, in the long-run, for this subset of models, Kyoto-only and total forcing are roughly equivalent metrics. Fig. 6 shows the relationship between Kyoto-only forcing and total forcing across these models for two of the climate-action cases. The difference between Kyoto-only $\mathrm{CO}_{2}$-e equivalent concentration and full gas $\mathrm{CO}_{2}-$ e concentration was approximately 55 ppmv CO al., 2007). In the climate-action scenarios, the difference between the two versions of $\mathrm{CO}_{2}$-e concentration closes considerably over time in the models, particularly in the more stringent climate-action cases. In 2100 , total forcing ranges from roughly $10 \mathrm{ppmv} \mathrm{CO}_{2}$-e above Kyoto forcing in the MESSAGE-NoBECS 450 ppmv $\mathrm{CO}_{2}$-e scenario to roughly 25 ppmv $\mathrm{CO}_{2}$-e below Kyoto forcing in the MiniCAM 550 ppmv $\mathrm{CO}_{2}$-e scenarios. This convergence, and the general lack of bias in the relationship between the two forcing metrics, suggests that there would be minimal difference between long-term results if the long-

\footnotetext{
${ }^{8}$ See Footnote 4.
}

term targets in the EMF 22 International Scenarios had been specified in total forcing rather than Kyoto-only forcing. The difference between the two is negligible compared to other uncertainties that are relevant over the 100 -year time horizon of the study.

There are several reasons for the convergence between the total forcing and Kyoto forcing. Many non-Kyoto, long-lived GHGs are regulated under the Montreal Protocol and therefore will largely be phased out by 2010 (CFCs and other gases) and 2040 (HCFCs) (UNEP Ozone Secretariat, 2006). Aerosol emissions are also strongly reduced as a co-benefit of GHG mitigation, since they occur in combustion processes of fossil fuels as well as traditional biomass. In addition, because aerosols are local pollutants with numerous adverse environmental and health effects (Smith and Haigler, 2008), they are likely to be reduced in the medium-term because of increasingly stringent air pollution legislation (e.g. Cofala et al., 2007). However, it should be emphasized that there is no strict physical link between the emissions of the different substances; for example, reduction of local air pollutants can be achieved without GHG mitigation, while some biofuels would increase emissions of such air pollutants.

Although there is convergence between Kyoto-only and total forcing in the long term, there are significant short-term differences between the two, and these are particularly relevant to the challenge of meeting the not-to-exceed 450 ppmv $\mathrm{CO}_{2}$-e scenario. On the one hand, with a lower initial $\mathrm{CO}_{2}$-e concentration, the not-to-exceed 450 ppmv $\mathrm{CO}_{2}$-e target would initially appear easier to meet if the 
target were based on total forcing rather than Kyoto-only forcing. On the other hand, in case of very rapid mitigation that is required to stay below 450 ppmv $\mathrm{CO}_{2}$-e in either of the two radiative forcing definitions, the decrease of aerosol emissions as a by-product of GHG mitigation would induce a strong increase of total radiative forcing, because aerosol cooling ceases almost immediately (Smith et al., 2000; Smith and Wigley, 2006; Krey and Riahi, 2009-this issue). Hence, it is not possible to determine, without further analysis, how the use of a total forcing metric would alter the conclusions for the not-to-exceed 450 ppmv $\mathrm{CO}_{2}$-e scenario in this study.

The second important observation is that transient temperature change lags equilibrium temperature change, with implications for the challenge of meeting particular temperature goals. The lag is due to the long time scales involved in such climate feedback mechanisms as ice-albedo and ocean thermal inertia. For example, in the overshoot 450 ppmv $\mathrm{CO}_{2}$-e cases and the not-to-exceed 550 ppmv $\mathrm{CO}_{2}$-e cases, both with full participation, the transient temperature change lags the steady-state equilibrium temperature change by $0.5^{\circ} \mathrm{C}$ or more throughout the century, assuming a climate sensitivity of $3{ }^{\circ} \mathrm{C}$ (Fig. 7). The practical implication is that, under a climate sensitivity of $3^{\circ} \mathrm{C}$, overshoot scenarios leading to 450 ppmv $\mathrm{CO}_{2}$-e Kyoto are consistent with limiting the increase in transient temperature to $2{ }^{\circ} \mathrm{C}$, as long as the overshoot is limited. Indeed, end-of-century concentrations slightly above $450 \mathrm{ppmv} \mathrm{CO}_{2}$-e might also be consistent with a $2{ }^{\circ} \mathrm{C}$ target, particularly if overshoot over the course of the century is limited. A 550 ppmv $\mathrm{CO}_{2}$-e goal is not consistent with limiting the increase in temperature to $2{ }^{\circ} \mathrm{C}$ at a climate sensitivity of $3{ }^{\circ} \mathrm{C}$. However, end-of-century targets well in excess of $550 \mathrm{ppmv} \mathrm{CO}_{2}$-e are consistent with limiting the temperature increase to $3{ }^{\circ} \mathrm{C}$ or less if climate sensitivity is $3^{\circ} \mathrm{C}$. Of course, in all cases, continued mitigation beyond 2100 is necessary to maintain temperatures below these longterm targets: the scenarios demonstrate that the global economy will need to be almost fully decarbonized by 2100 , and mitigation policy is needed post-2100 to prevent the market from switching back to fossil fuels.

Finally, there is tremendous uncertainty surrounding climate sensitivity, the most fundamental factor linking the scenarios in this paper to temperature-related goals. Hence, linking the scenarios to specific temperature pathways based on specific estimates of climate sensitivity may be wholly inconsistent with a risk management approach to climate mitigation. The discussion of global temperature increase thus far has been based on a climate sensitivity of $3{ }^{\circ} \mathrm{C}$, which was considered most likely by the IPCC. Due to the large uncertainty of climate sensitivity, a comparison of single climate model runs is not sufficient to capture the scenario characteristics with respect to temperature change; rather, probabilistic assessment is needed (den Elzen and van Vuuren, 2007; Keppo et al., 2007; Meinshausen, 2006; Meinshausen et al., 2009; Schneider and Mastrandrea, 2005). Krey and Riahi (2009-this issue) explored the probabilistic temperature implications of the scenarios from IMAGE, MESSAGE and MiniCAM. The probability of staying below a temperature target over the course of the century is shown in the left-hand panel of Fig. 8 for the overshoot 450 ppmv $\mathrm{CO}_{2}$-e scenarios with full participation from the three models. Based on the uniform prior climate sensitivity probability density function from Forest et al. (2002), the authors find that the probability of staying below $2{ }^{\circ} \mathrm{C}$ over the course of the 21 st century varies enormously, between about $25 \%$ and $75 \%$ (Fig. 8). The range of likelihoods for staying below a temperature target turns out to be much narrower in the not-to-exceed $550 \mathrm{ppmv} \mathrm{CO}_{2}$-e scenarios. The large variation can be traced to the degree of overshoot in the scenarios, which is strongly linked to cumulative GHG emissions until 2050, as shown by Meinshausen et al. (2009). The right-hand panel of Fig. 8 displays the probability of staying below a $2{ }^{\circ} \mathrm{C}$ temperature increase until 2100 for the overshoot $450 \mathrm{ppmv}$ $\mathrm{CO}_{2}$-e scenarios with full participation. A range of probability estimates are shown, based on 12 probability density functions from

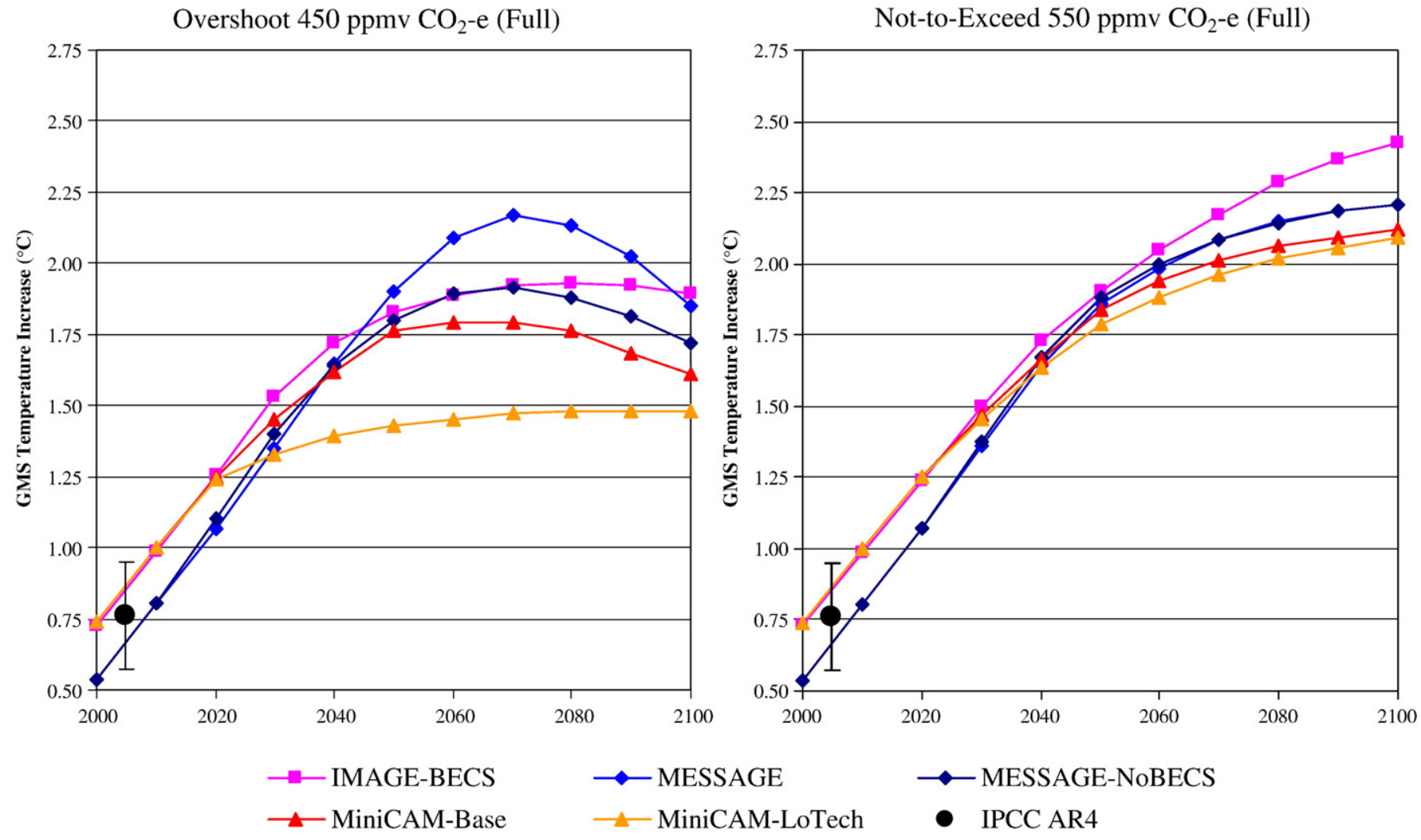

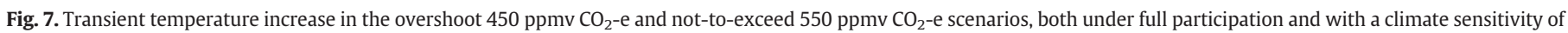
$3{ }^{\circ} \mathrm{C}$ from selected models (IMAGE, MESSAGE, and MiniCAM). The $90 \%$ confidence interval for temperature rise in 2005 is $\pm 0.19{ }^{\circ} \mathrm{C}$ (Trenberth et al. 2007 ). 


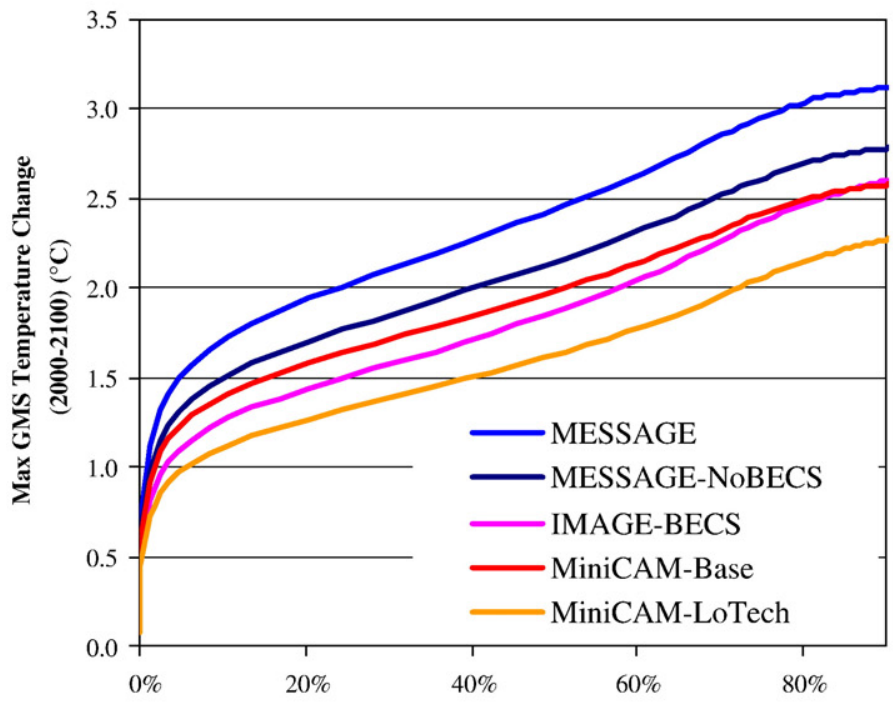

Probability of Staying Below GMS

Temperature Change Target (2000-2100)

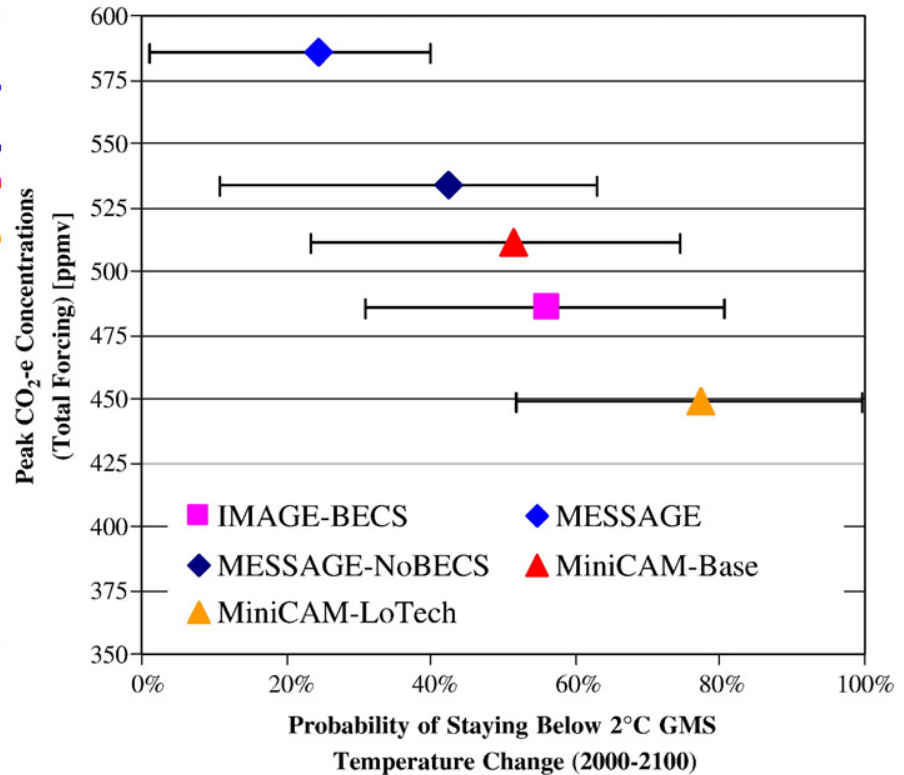

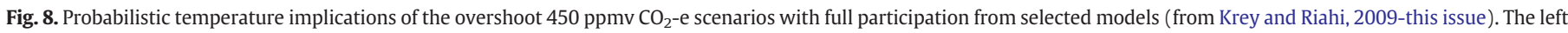

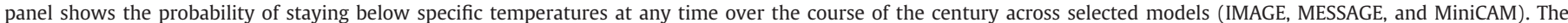

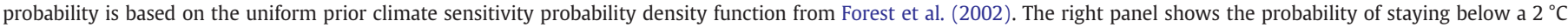

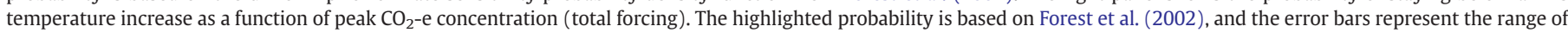

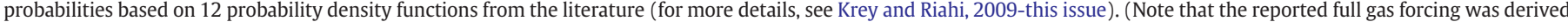

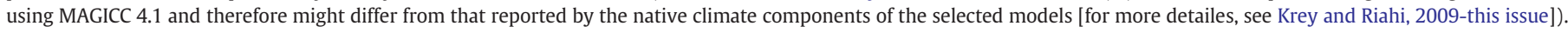

the literature. Probabilities are shown as a function of maximum total $\mathrm{CO}_{2}$-e concentration, which turns out to be a good proxy for estimating the likelihood of staying below $2{ }^{\circ} \mathrm{C}$ over the course of the century.

\section{Energy system transitions}

The energy system is the primary source of anthropogenic GHG emissions. A dramatic transformation in the way that human societies produce and use energy will therefore be core to any efforts to stabilize atmospheric concentrations of GHGs. At some point, all scenarios lead toward zero emissions and an associated reduction in freely-emitting fossil-based energy. The timing of this transformation depends on the stringency of the climate-related target.

There are two options for reducing emissions from the energy sector: (1) reducing energy consumption and (2) substituting from freelyemitting fossil energy to low-emissions sources: nuclear energy, fossil energy with CCS, bioenergy (with and without CCS), and non-biomass renewable energy such as wind power and solar power. Primary energy consumption in the reference scenarios (Fig. 9) sets the scale for the degree to which these two options must be deployed. All other things being equal, higher reference energy consumption leads to higher mitigation and mitigation costs in the climate-action cases, greater production from low- or negative-emissions sources, and larger reductions in energy consumption from the reference. More broadly, higher energy consumption in the reference makes reaching any concentration target more difficult. For example, reference energy consumption is in the upper half of the distribution for all of the models that could not provide not-to-exceed 550 ppmv $\mathrm{CO}_{2}$-e scenarios with delayed participation (GTEM, MERGE Optimistic, MESSAGE, MiniCAMBase, MiniCAM-LoTech, and Poles).

All of the EMF 22 scenarios are associated with increased annual primary energy consumption over the century. By 2100 , annual primary energy consumption ranges from more than a doubling from today's levels $(\approx 1100 \mathrm{EJ} / \mathrm{yr}$ ) in the lowest primary energy future - the MERGE Pessimistic reference scenario, which is based on severe recession followed by low growth post-recovery - to almost quadruple today's levels $(\approx 1900 \mathrm{EJ} / \mathrm{yr})$.
The requirement for low-carbon energy and energy use reductions is simply the difference between reference energy and the energy that can still be supplied by freely-emitting fossil fuels while still maintaining a course toward long-term concentration goals. Unlike reference primary energy, which varies dramatically across models, depending in large part on economic growth, the freely-emitting fossil energy consumption is largely constrained by the degree of emissions reductions (Fig. 10). Hence, the relationship between freely-emitting fossil energy and emissions reductions is roughly linear across the full set of scenarios. Variations in freely-emitting fossil energy for any given degree of emissions reductions are due in large part to differences among models in the degree of fuel switching among fossil sources and the presence or absence of the option for bioCCS, which allows for greater consumption of freely-emitting fossil energy for a given level of $\mathrm{CO}_{2}$ emissions.

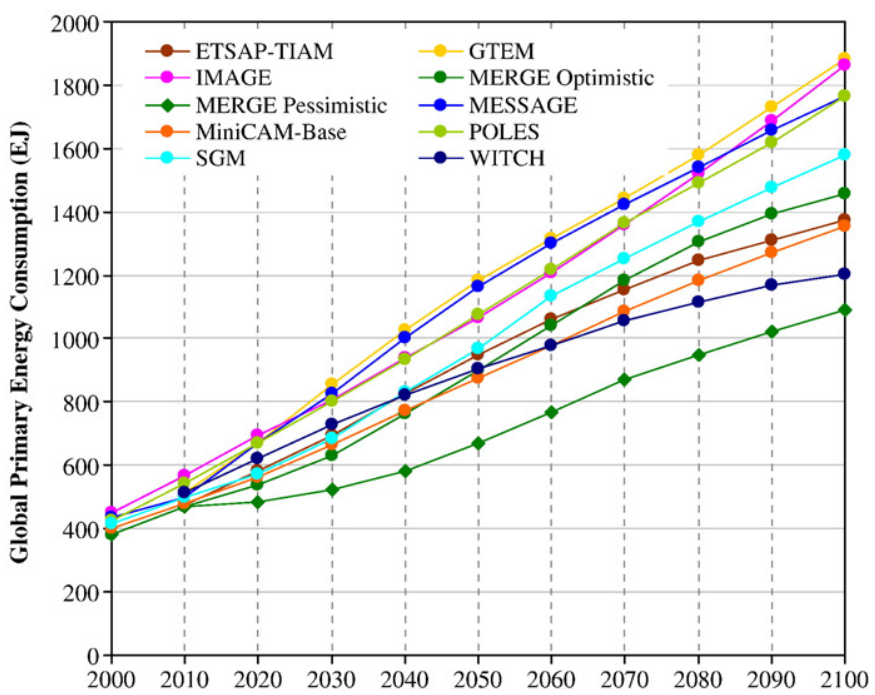

Fig. 9. Reference global primary energy consumption across EMF 22 scenarios. Note that nuclear and non-biomass renewable energy sources are expressed in fossil-equivalent primary energy consumption based on a conversion factor of 0.4 . 

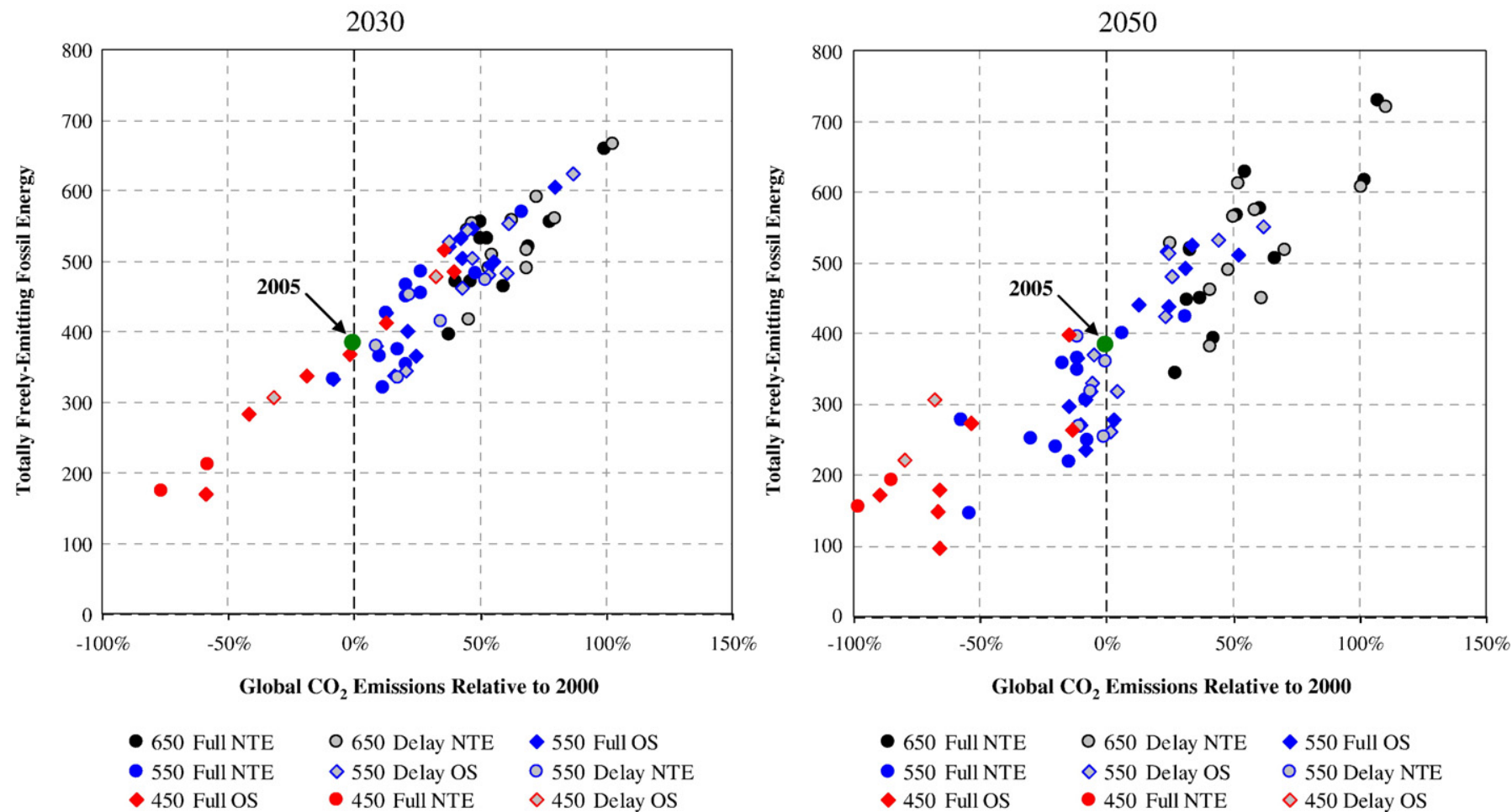

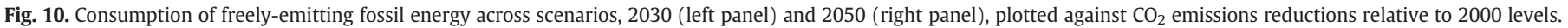

Low-carbon energy is what remains after freely-emitting fossil energy and energy reduction are subtracted from reference energy consumption. Consistent with intuition, the tighter constraints are associated with greater emissions reductions, and greater emissions reductions are associated with greater production from low- and negative-emissions sources (Fig. 11).

The production of low-carbon primary energy in these scenarios demonstrates the scale of the challenge presented by the climate-action
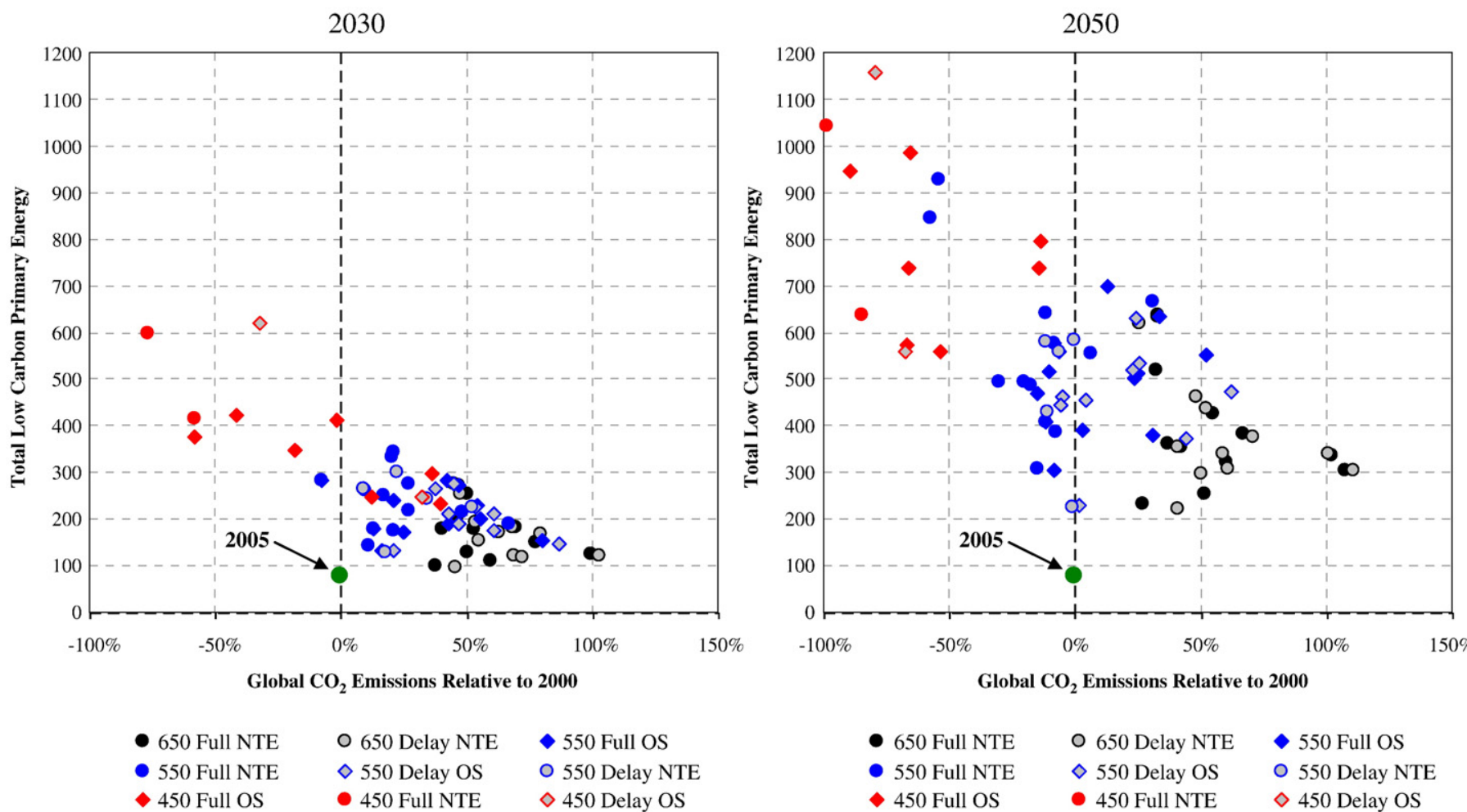

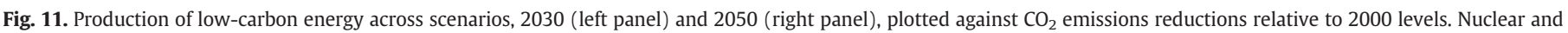
non-biomass renewable energy sources expressed in fossil-equivalent primary energy consumption based on a conversion factor of 0.4 . 
2030

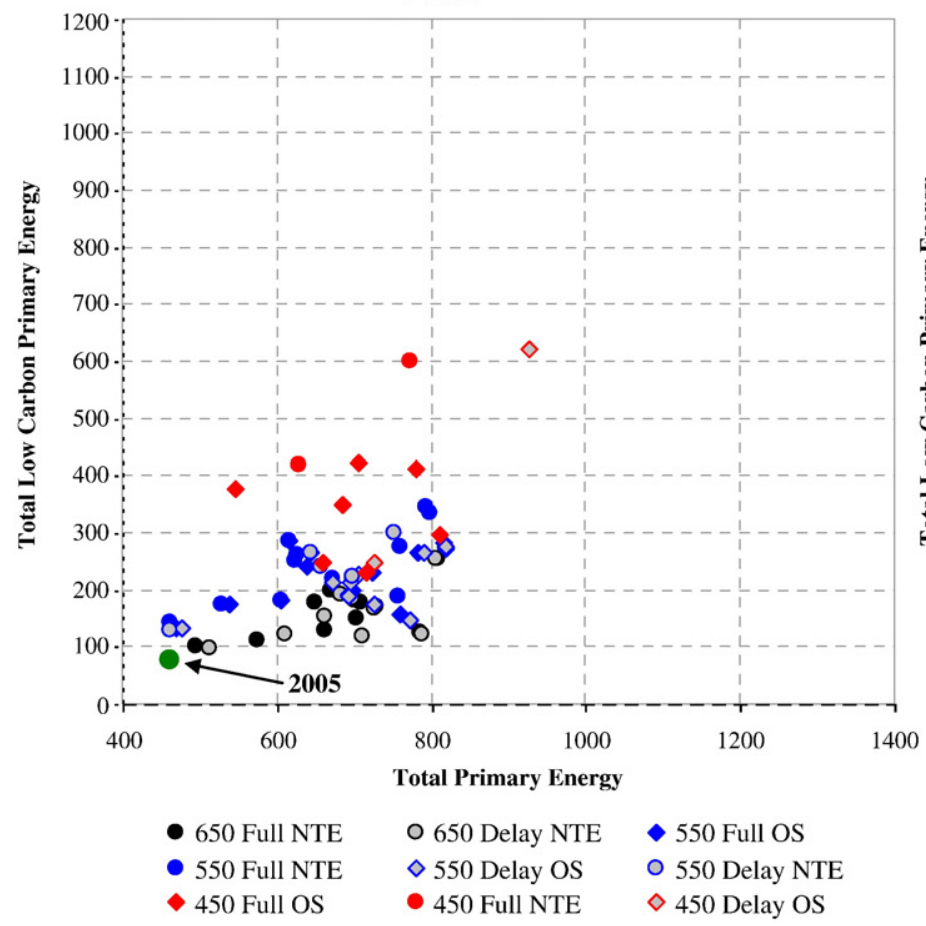

2050

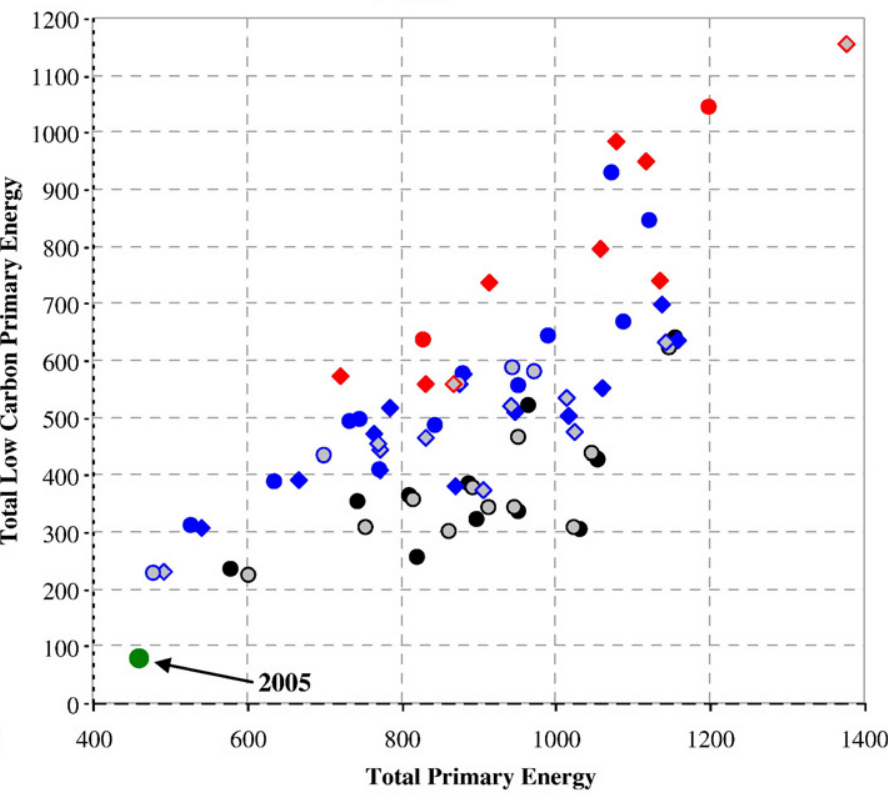

$\begin{array}{lll}\text { - 650 Full NTE } & \text { ○ 650 Delay NTE } & \diamond 550 \text { Full OS } \\ \text { - 550 Full NTE } & \diamond 550 \text { Delay OS } & \text { ○ 550 Delay NTE } \\ \bullet \text { 450 Full OS } & \bullet \text { 450 Full NTE } & \diamond 450 \text { Delay OS }\end{array}$

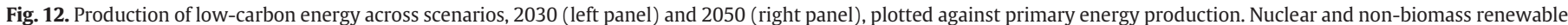
energy sources expressed in fossil-equivalent primary energy consumption based on a conversion factor of 0.4.

cases. In 2005, primary energy consumption from low-emissions sources (converted here to fossil-equivalent and excluding traditional biomass) stood at roughly $75 \mathrm{EJ} / \mathrm{yr}$. In 2030 , production from lowemissions sources in the EMF 22 International Scenarios ranges from $200 \mathrm{EJ} / \mathrm{yr}$ to $600 \mathrm{EJ} / \mathrm{yr}$ for the $450 \mathrm{ppmv} \mathrm{CO}_{2}$-e scenarios; that is a range of slightly less than triple 2005 levels to an eight-fold increase. Consumption in the 550 ppmv $\mathrm{CO}_{2}$-e scenarios ranges from $100 \mathrm{EJ} / \mathrm{yr}$ to over $300 \mathrm{EJ} / \mathrm{yr}$. In 2050, production from low-emission sources ranges

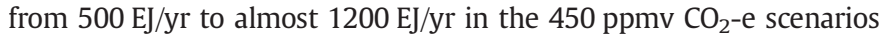
and from $200 \mathrm{EJ} / \mathrm{yr}$ to over $900 \mathrm{EJ} / \mathrm{yr}$ in the $550 \mathrm{ppmv} \mathrm{CO}_{2}$-e scenarios. These represent massive ramp-ups in the scale of low-emissions energy production, and a marked departure from recent trends.

As an illustration of the extent of the changes implied by the more aggressive scenarios, the MiniCAM not-to-exceed $450 \mathrm{ppmv} \mathrm{CO}_{2}$-e scenario with full participation included 500 new 1000 MW nuclear reactors by 2020 along with the storage of 20 billion tonnes of $\mathrm{CO}_{2}$ (Calvin et al., 2009a-this issue). The overshoot 450 ppmv $\mathrm{CO}_{2}$-e scenario with full participation included 126 new 1000 MW nuclear reactors by 2020 along with the capture of nearly one billion tonnes of $\mathrm{CO}_{2}$.

Consumption of low-emissions energy is a function not just of the degree of emissions reductions, but also of the scale of the total energy system (Fig. 12). For every primary energy level, the production of low-emissions energy increases with the stringency of the constraint. Note that the higher primary energy in the 450 ppmv $\mathrm{CO}_{2}$-e scenarios is a function largely of the character of the models that were capable of producing those scenarios rather than any sort of increasing relationship between primary energy and long-term concentration level. ${ }^{9}$

\footnotetext{
${ }^{9}$ The one exception to this is the ETSAP-TIAM scenarios, in which primary energy increased with the stringency of the stabilization level because the model implements large increases in electricity production from biomass-fired and coal-fired plants with CCS, both of which have relatively low efficiencies.
}

\section{Economic implications}

\subsection{Carbon prices and economic costs}

Table 5 reports the Group 1 carbon prices in 2020 across scenarios. Consistent with intuition, the results indicate that initial carbon prices increase with the stringency of the concentration target, are higher with delayed participation than full, immediate participation, and are lower if there is an opportunity to overshoot the concentration goal. Carbon prices in 2020 are roughly $\$ 50 / \mathrm{tCO}_{2}$ or below for both 650 ppmv $\mathrm{CO}_{2}$-e cases as well as the 550 ppmv $\mathrm{CO}_{2}$-e cases with full participation only. However, higher price signals are needed for the more ambitious climate-action cases. For example, 2020 carbon prices for the not-toexceed 550 ppmv $\mathrm{CO}_{2}$-e scenario with delayed participation exceed $\$ 100 / \mathrm{tCO}_{2}$ for three of the six models that were able to achieve this case. The prices could be reduced by following an overshoot pathway to the concentration target or through immediate participation, though immediate participation would require Groups 2 and 3 to take on substantive near-term emissions reductions.

The present values of total global costs over the century are shown in Table 6 . The calculations are based on a $5 \%$ discount rate. Note that because the cost estimates are based on different metrics of cost from different models, they are not strictly comparable. In general, the cost information exhibits similar behavior to the carbon prices: the climate objective, the nature of international participation and the possibility to overshoot the stabilization target are significant determinants of global policy costs. Across models, costs range into the tens of trillions of U.S. dollars (2005\$).

One characteristic of both the price and cost results is the wide range of values across models. This variation reflects differences in the underlying characteristics of the models, including variations in the forces that lead to GHG emissions (e.g., economic growth) as well as the flexibility of the energy and underlying systems to make the adjustments necessary to reduce emissions. It is important to note that differences in the ability to reduce emissions are determined not just by the energy technology and other options available today, but 
Table 5

Carbon prices in Group 1 in $2020\left(2005 \$ / \mathrm{tCO}_{2}\right)$ across scenarios.

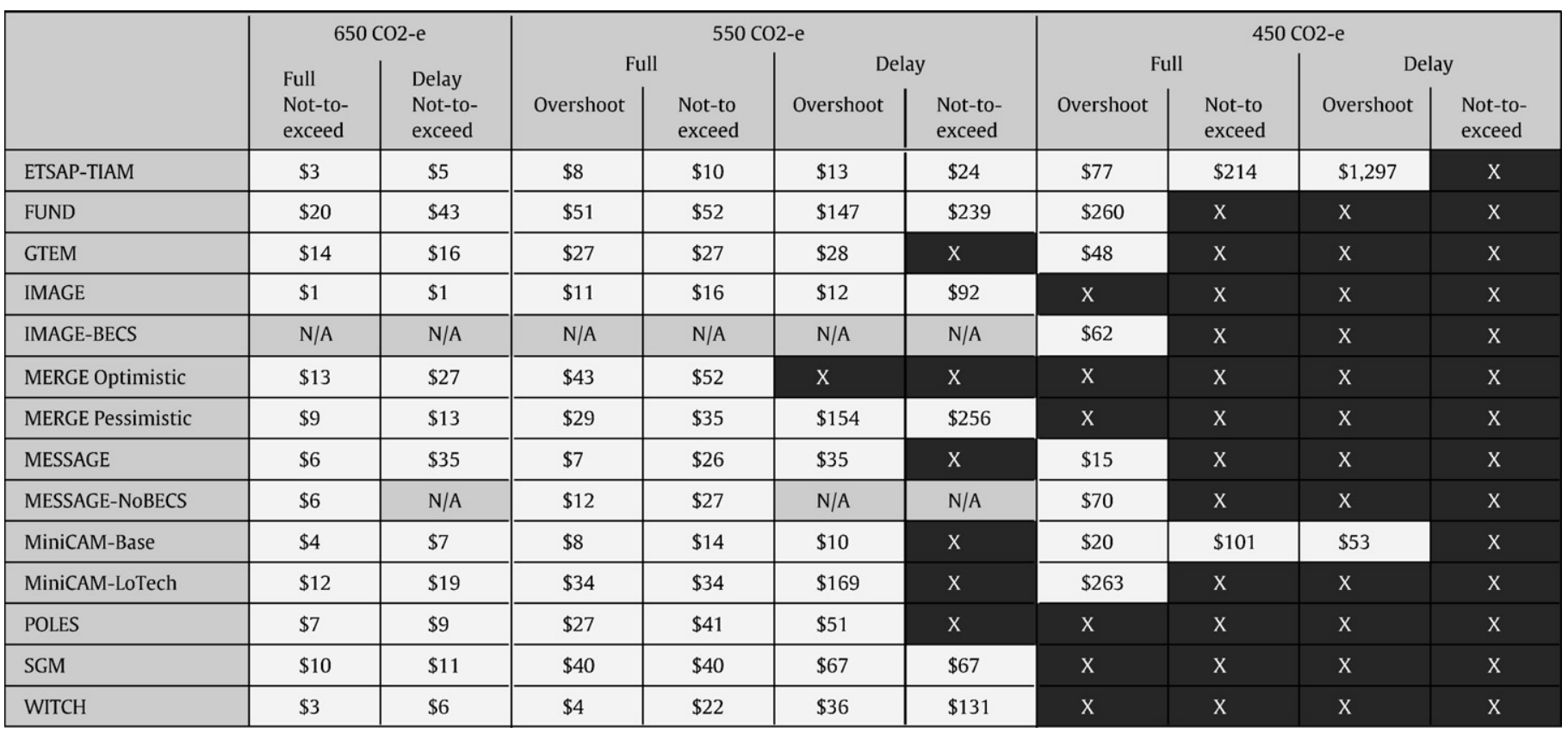

2020 carbon prices for Group 2 and 3 are the same as those in the table for the full participation scenarios and zero in the delayed participation scenarios. Darkened cells with an "X" mean that the team was not able to produce the scenario. "N/A" means that the scenario was not attempted with the given model or model version.

also those available decades into the future. Even 2020 carbon prices are a reflection of the technology options that will be available in the model throughout the study period; all else being equal, the expectation of more limited technology options beyond 2050 would call for greater mitigation in 2020 and therefore a higher carbon price (Clarke et al., 2007). Future technology options are highly uncertain, and the variation in prices and costs across models is to a large degree a reflection of this underlying technology and system uncertainty. This is in addition to variations in assumptions about the rate at which the energy system can be transformed in the near-term. In addition, the timing of participation by Group 2 and Group 3 is not precisely aligned across models, as noted in Table 2, and this explains some of the variation in the impact of delayed participation.
The forces that lead to variability in prices and costs (in addition to differences in cost metrics) are the same as those that influence whether or not models were successful in producing the more challenging climate-action cases. Because of this, the variation in prices and costs among climate-action cases should be interpreted with some caution. Only subsets of the participating models were able to produce scenarios associated with the more stringent climate-action cases, so the robustness of the results decreases with the stringency of the climateaction cases. Indeed, the exclusion of models that were not successful in producing the more challenging climate-action cases inherently biases the reported carbon prices and economic costs downward. Those models that were able to produce the more challenging scenarios are generally those that lie toward the lower end of the range of costs across

Table 6

Present value of global economic policy costs discounted at a 5\% discount rate (trillion 2005\$) across scenarios.

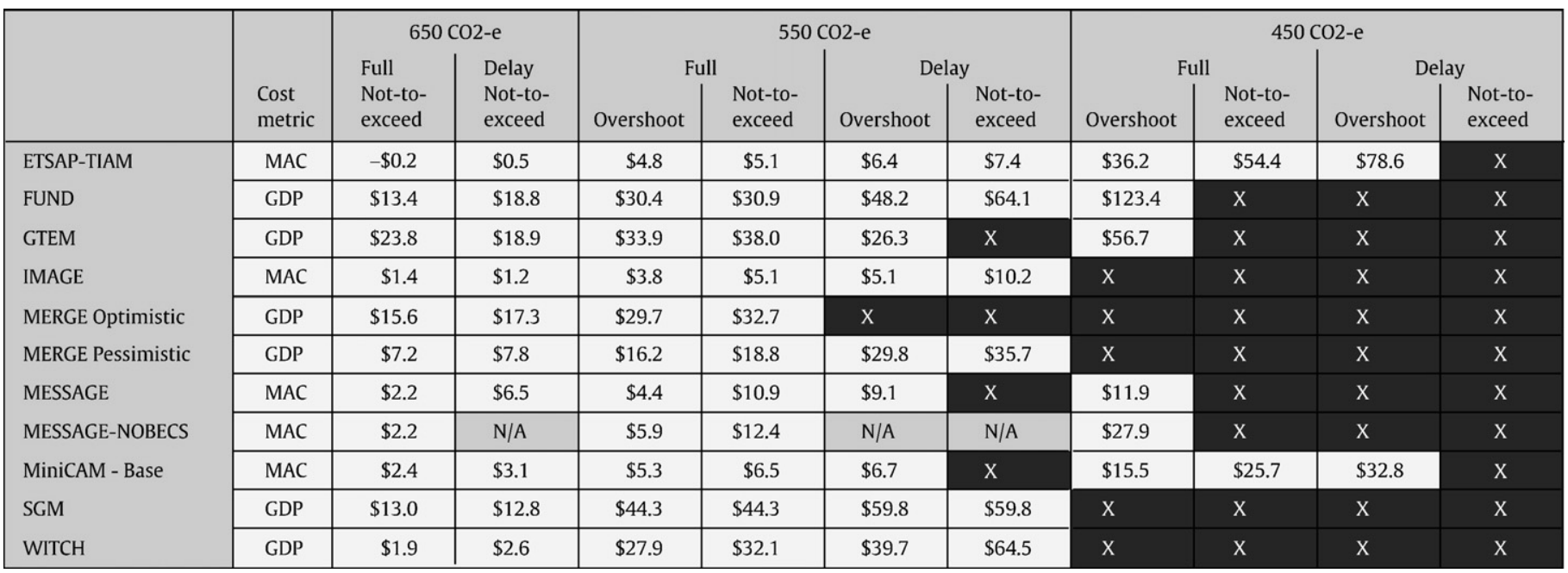

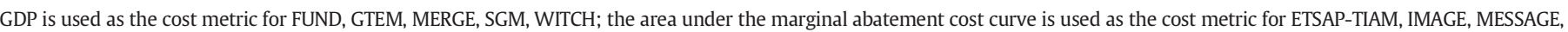

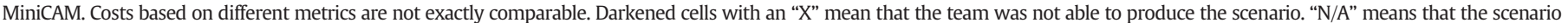
was not attempted with the given model or model version. 
scenarios. For example, the two models that were able to achieve both the not-to-exceed $450 \mathrm{ppmv} \mathrm{CO}_{2}$-e case with full participation and the overshoot 450 ppmv $\mathrm{CO}_{2}$-e case with delayed participation (ETSAPTIAM and MiniCAM) have the lowest carbon prices for the not-toexceed 550 ppmv $\mathrm{CO}_{2}$-e case with full participation. If those models that generally exhibit higher prices were to model the more challenging climate-action cases, an expected outcome would be higher price ranges for these more challenging cases. Similarly, if the models with low carbon prices adopted more conservative technology assumptions, their prices would be expected to rise. The implication of technology assumptions is illustrated by the difference in prices and costs between the MESSAGE and MESSAGE-NoBECS scenarios (Krey and Riahi, 2009this issue) and the MiniCAM-Base and MiniCAM-LoTech scenarios (Calvin et al., 2009a-this issue).

The price and cost results clearly demonstrate that delayed participation will adversely affect the global economic costs of meeting a given climate objective. The additional penalty is expected to fall mostly on the Group 1 countries, as those are the ones that would need to compensate for the lost mitigation in Group 2 and Group 3. However, it is important to note that delayed participation does not necessarily decrease costs for the late entrants. Many of the participating models find that in addition to Group 1, the Group 2 (BRICs) countries might also pay a higher cost (in present value terms) if a particular concentration goal is to be met and these countries delay mitigation. For example, across most models and for most climate-action cases, China's policy cost increases in the case of late participation (Fig. 13). This is the result of two interacting factors. First is the fact that a delayed participation would postpone the participation of Group 3 by a further 20 years, meaning that China would not be among the very last participants in mitigation and would therefore have to take on some of the burden of later entrants, just as Group 1 does throughout the delayed participation scenarios. Second, and more generally, although delayed participation produces an initial period in which no mitigation is undertaken and no costs are incurred, it leads to more rapid and aggressive reductions after a country begins mitigation, assuming a particular concentration target is still to be met; and this mitigation will take place starting from whatever carbonintensive technologies and infrastructures were put in place during the no action period. This second effect depends greatly on the assumption for the delayed participation scenarios that no mitigation takes place prior to accession. Section 6.3 discusses how costs could be reduced if the Group 2 and Group 3 countries were to anticipate their future mitigation requirements.

\subsection{The potential magnitude of wealth transfers implied to spur participation}

The discussion to this point has sidestepped the issue of emissions allocations or financial transfers among regions and countries in order to achieve the climate-action cases. One reason for this is that it is well established in economics that the distribution of the cost can be separated in principle from emissions mitigation through various mechanisms such as income transfers or - in the context of cap-andtrade regimes - the assignment of emissions allocations. At the same time, the adverse economic implications of delayed international participation in the delayed participation climate-action cases indicate a need for incentives to induce a broad cooperation. It is therefore useful to explore the general magnitude of the financial transfers involved in achieving full participation. To shed light on this issue, a subset of modelling teams computed the financial transfers that would be required to leave Group 2 and Group 3 regions just as well off under a scenario in which they began emissions mitigation simultaneously with Group 1 regions, as they would have been by delaying participation. The models conducted this experiment by assuming an international carbon market in which non-participating countries are allocated their baseline emissions. Fig. 14 reports the resulting financial transfers from Group 1 to Group 2 and Group 3 (equal to the annual carbon price multiplied by the quantity of carbon traded) from 2020 to 2050. Transfers are found to increase with the stringency of the climate objective, mostly because of the rising carbon prices. Some models find that the possibility to overshoot the stabilization target reduces the financial flows, but in general the monetary transfers in the $550 \mathrm{ppmv} \mathrm{CO}_{2}$-e case are found to be quite significant, in the range of several hundred billions of U.S. dollars per year. At these levels, the carbon market would eventually resemble a large commodity market such as the oil market. For example, at a price of $\$ 50 /$ barrel, Group 1 oil imports today equal roughly $\$ 0.5$ trillion (2005\$); this value is obtained in the carbon market by all models by mid century in the 550-e climate-action cases.

Fig. 14 also provides an indication of the recipients of the transfers. The largest share is shown to mostly go to Group 3, which faces the more distant commitment. Group 2 would only receive transfers prior

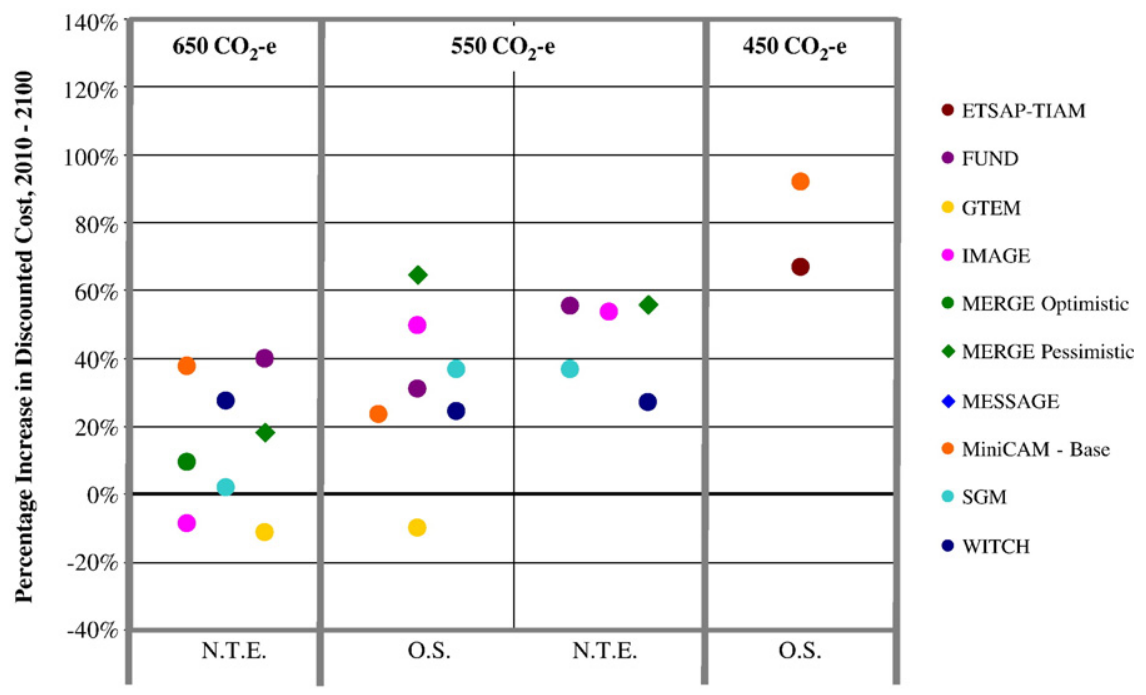

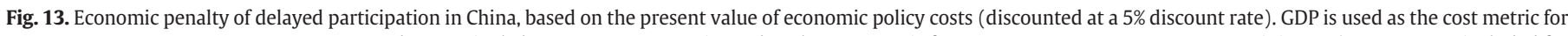

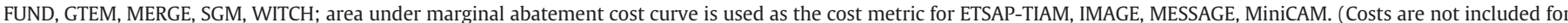

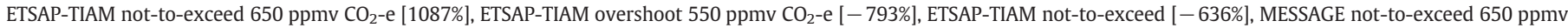

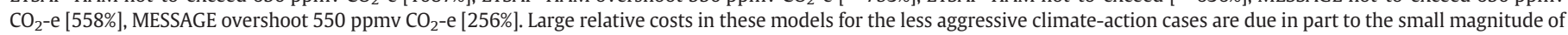
the costs in general for these climate-action cases.) 


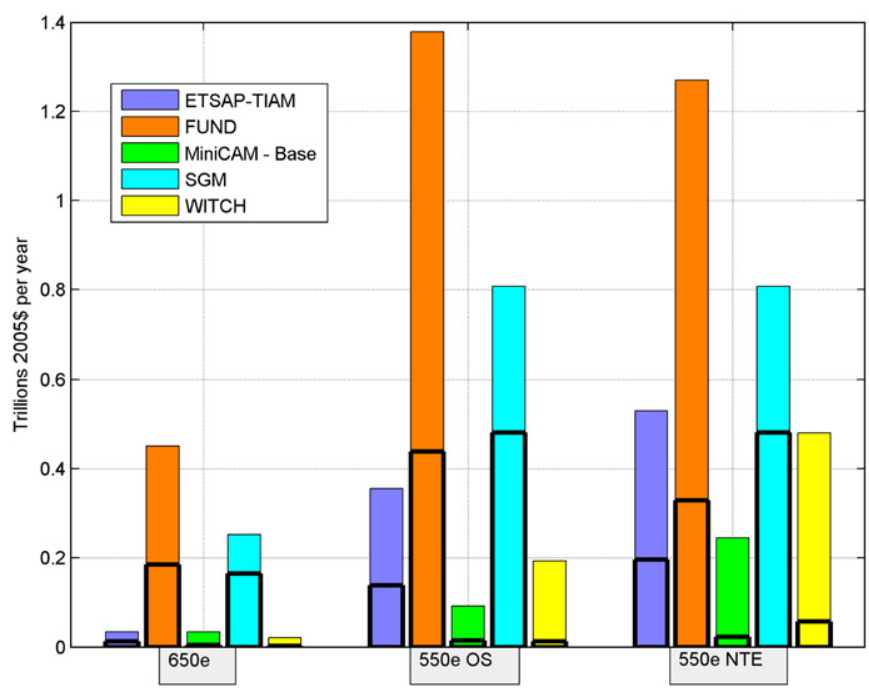

Fig. 14. Average financial transfers out of Group 1 (OECD) in an international carbon market from 2020 to 2050, calculated as undiscounted averages. The lower blackened part of each bar represents the transfers to Group 2 (BRICs).

to 2030 - a period in which transfers would be relatively small. Group 2 generally becomes a buyer of permits after they join the climate coalition in 2030.

\subsection{The role of policy anticipation}

The delayed participation scenarios in EMF 22 are based on the assumption that non-participatory regions undertake no mitigation prior to accession. This raises the question of whether the downsides of delayed participation could be reduced if non-participatory countries were to agree, during negotiations, to the timing and magnitude of reductions, even though such reductions would not begin until some future date. Two intertemporal models that can be run with and without foresight (i.e., intertemporal optimization) ran this experiment, MERGE (Blanford et al., 2009-this issue) and WITCH (Bosetti et al., 2009-this issue). Specifically, the experiment assumed that Group 2 (BRICs) would agree now to join the coalition post-2030 and Group 3 post-2050. Neither would commit to reductions prior to accession, but both would be allowed to configure their capital stock, and make the associated emissions reductions, in anticipation of their future commitments. The costs from this experiment were then compared with those under the assumption that Group 2 and Group 3 followed their baseline prior to participation.

Table 7 below shows the reduction in costs in the two models due to entering into an agreement today, and acting in anticipation of such entry, even though actual obligations do not begin until a future date. If Group 2 is going to enter the coalition at a given date in the future, it is in their best interest to anticipate their future mitigation, rather than enter with a poorly configured capital stock. This would certainly be the case if they stayed on their BAU path until the commitment date. When the Group 2 countries prepare in advance for a post-2030 accession, the present value of GDP losses is reduced by $31 \%$ and $23 \%$, in MERGE and WITCH, respectively. This results from gradually moving to a lower carbon energy system prior to accession, thereby reducing the degree of turnover in the energy system that might be required after accession.

\section{Table 7}

Cost savings (costs expressed as present value of GDP losses) under delayed participation with and without anticipation of the future mitigation commitment in the not-to exceed $550 \mathrm{CO}_{2}$-e climate-action case (MERGE Pessimistic is used for the MERGE scenarios).

\begin{tabular}{|c|c|c|c|}
\hline \multicolumn{2}{|l|}{ Group 1} & \multicolumn{2}{|c|}{ Group 2 (BRICs) } \\
\hline MERGE & WITCH & MERGE & WITCH \\
\hline $51 \%$ & $46 \%$ & $31 \%$ & $23 \%$ \\
\hline
\end{tabular}

The Group 1 countries also benefit from anticipation and associated early mitigation by Group 2 and Group 3. Their losses are reduced by approximately one-half in both models, which is more substantial than the degree of emissions reduction that they achieve in the anticipation cases (see Bosetti et al., 2009-this issue; Blanford et al., 2009-this issue). This highlights the non-linear nature of abatement costs. Initial reductions in Group 1 are less expensive than those associated with filling the gap left by developing country non-participation in coming decades.

\section{Additional issues addressed by the scenarios}

In addition to modeling the coordinated scenarios, participating modeling teams were encouraged to pursue supplemental insights via additional scenarios. This section summarizes a number of insights and directs readers to the relevant papers for details. This section is by no means exhaustive in cataloging the insights that can be gleaned from all the papers in this volume.

Several modeling groups explored the role of specific technologies, such as CCS, nuclear, energy efficiency, and bioCCS. These analyses explored the implications of different combinations of available technologies. Krey and Riahi (2009-this issue), for example, find that the overshoot $450 \mathrm{CO}_{2}$-e scenario $\left(2.6 \mathrm{~W} / \mathrm{m}^{2}\right)$ with immediate global participation is unattainable without CCS with the MESSAGE model. In contrast, Calvin et al. (2009a-this issue) find that the target is still attainable but it requires 1100 new $1000 \mathrm{MW}$ nuclear reactors in 2020. Blanford et al. (2009-this issue) find that diffusion of new technologies to developing countries increases the value of these technologies substantially. While R\&D has a high payoff domestically, the payoff globally is an order of magnitude higher. Bosetti et al. (2009this issue) find that delayed participation initially increases the R\&D effort by exerting additional pressure on the knowledge base in developed economies, but ultimately leads to reduced technical change and deployment of low-carbon technologies.

Uncertainties were also evaluated across the papers in this volume via a variety of approaches. Most studies considered uncertainties with deterministic sensitivity analysis of, for instance, available technologies and alternative baselines. For example, Krey and Riahi (2009-this issue), Calvin et al. (2009a,b-this issue), Blanford et al. (2009-this issue), and van Vliet et al. (2009-this issue) explore the implications of technology availability. Blanford et al. (2009-this issue) also explore the implications of economic growth, and a recession in particular. They find that a near-term recession does not fundamentally alter the nature of the climate management challenge. Other papers explore uncertainty using more formal treatments. Krey and Riahi (2009-this issue) laid climate sensitivity uncertainties over radiative forcing pathways to evaluate the likelihood of exceeding temperature objectives. Loulou et al. (2009-this issue) used stochastic modeling to explore optimal hedging strategies given alternative possible resolutions of climate sensitivity. The authors find that the uncertainties in the resulting climate and the significantly higher costs associated with achieving the $450 \mathrm{ppmv} \mathrm{CO}_{2}$-e targets provide justification for hedging and implementing stronger early mitigation action. Tol (2009-this issue) creates 170,000 policy scenarios to explore the feasibility of stringent targets, systematically varying the price of carbon, participation in climate policy, the strength of the climate feedback on the terrestrial carbon cycle, the no-policy scenario, and the abatement costs.

A few papers commented specifically on leakage. Delayed regional participation raises important questions about potential leakage of both production and emissions. Gurney et al. (2009-this issue) find both kinds of leakage to non-OECD countries with energy-intensive goods and agricultural production, which has implications for emissionintensive commodity trade and international flows of investment funds. Meanwhile, Calvin et al. (2009b-this issue) find that industrial leakage to non-participating regions is less than $10 \%$ when all regions of the world begin emissions mitigation by 2050 . Bosetti et al. (2009-this 
issue) also report relatively small international leakage in industrial emissions. However, Calvin et al. (2009a-this issue) find that leakage in agricultural sectors and therefore in emissions from land use change could be substantial and potentially larger than industrial leakage.

Several groups focused on alternative policy structures or goals to those in the main body of core scenarios. Russ and van Ierland (2009this issue) explored scenarios that allow for differentiated participation of developing countries from 2012 onwards and a gradual development of a carbon market. They find that costs were decreased substantially compared to the delayed participation scenarios in which major countries delay their participation to after 2030. Van Vliet et al. (2009-this issue) explored the implications of radiative

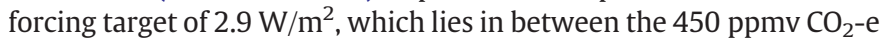
and 550 ppmv $\mathrm{CO}_{2}$-e targets. Russ and van Ierland explored the implications of a $3.1 \mathrm{~W} / \mathrm{m}^{2}$ radiative forcing target.

Additional extensions beyond those discussed above include the role of non- $\mathrm{CO}_{2}$ GHGs (Krey and Riahi, 2009-this issue; Calvin et al., 2009a-this issue), the implications of uncertainty in the behavior of the global terrestrial biosphere (Tol, 2009-this issue), and optimal mitigation in a cost-benefit framework (Tol, 2009-this issue).

\section{Summary}

Stabilizing the global climate will require a very different world than the one we live in today. The EMF 22 International Scenarios have explored the interactions between three factors that influence how the future might evolve: the long-term target, the timing and nature of international participation in climate mitigation, and the degree to which the target might be temporarily exceeded.

In general, the results from this study confirm intuition about these forces and their interactions. The challenge of mitigation increases with the stringency of the target, and the more ambitious of the climate-action cases explored in this study are particularly challenging. Even with overshoot and immediate and comprehensive international action, only eight of 14 models were successful in producing scenarios that met the 450 ppmv $\mathrm{CO}_{2}$-e target by 2100 due to the large and rapid changes required in energy and related systems to meet this ambitious target. Only two models could produce this climate-action case assuming delayed participation. No model was able to meet the not-to-exceed $450 \mathrm{ppmv} \mathrm{CO}_{2}$-e assuming delayed participation. Similarly, a number of models were not successful in producing scenarios for the 550 ppmv $\mathrm{CO}_{2}$-e targets under delayed participation. Despite these challenges, a number of models did produce scenarios for many of the more ambitious climate-action cases; these scenarios provide valuable guidance on how such ambitious targets might be achieved, and they demonstrate the exceptional speed and magnitude of the associated changes in energy and related systems.

A failure to develop a comprehensive, international approach to climate mitigation will constrain efforts to meet ambitious climaterelated targets. Without early, comprehensive action by major emitting regions, concentrations may exceed particularly ambitious targets such as 450 ppmv $\mathrm{CO}_{2}$-e and even 550 ppmv $\mathrm{CO}_{2}$-e. Furthermore, in shifting emissions mitigation toward those countries taking early action (Group 1 in this exercise), emissions reductions may be required in those countries that are well beyond what they are willing to bear in the nearterm. Regardless of the target, the global costs of achieving any longterm climate-related target will be higher without comprehensive action, and they may be higher not just for the initial entrants but also for those that join along the way.

The ability to temporarily exceed, or overshoot, long-term goals may make some of the more stringent long-term climate limitation goals more achievable and lessen the impacts of a failure to achieve comprehensive action, but these pathways come at a cost. Overshoot pathways will lead to greater environmental consequences than pathways that keep concentrations below their long-term goal. In addition, because they shift emissions mitigation from the present to the future, they also come with the risk that future emissions reductions of the scale needed to meet the goal may not materialize.

This study leaves many questions unanswered. It does not address the wide range of possible policy approaches for mitigation, including both different regional responsibilities than those explored in this study and non-price-based mechanisms, such as technology standards and sectoral policies. Although these scenarios comment on the requirements for meeting particular temperature goals, they are not designed specifically to explore temperature goals or other potentially relevant goals (e.g., ocean $\mathrm{pH}$ ). The scenarios provide insight into the technology deployment elements of mitigation futures, but not into the means to achieve technology development and diffusion. A great deal of research remains to be done to truly understand the character of future worlds, and future energy systems in particular, that must be very different from those of today, if climate goals such as those examined in this study are to be realized. Continuing research will help to inform these and other issues, and to provide timely and relevant information as the community of the world's nations moves forward with individual and collective actions to address climate change.

\section{References}

Blanford, G.J., Richels, R.G., Rutherford, T.F. 2009. Feasible climate targets: the roles of economic growth, coalition development and expectations. Energy Economics 31, S82-S93 (this issue).

Bosetti, V., Carraro, C., Tavoni, M., 2008. Delayed participation of developing countries to climate agreements: should action in the E.U. and U.S. be postponed? Fondazione Eni Enrico Mattei, Working Paper N.70-2008.

Bosetti, V., Carraro, C., Tavoni, M. 2009. Climate change mitigation strategies in fast-growing countries: the benefits of early action. Energy Economics 31, S144-S151 (this issue).

Calvin, K., Edmonds, J., Bond-Lamberty, B., Clarke, L., Kim, S.H., Kyle, P., Smith, S.J., Thomson, A., Wise, M. 2009. 2.6: Limiting climate change to $450 \mathrm{ppm} \mathrm{CO}_{2}$ equivalent in the 21st century. Energy Economics 31, S107-S120 (this issue).

Calvin, K., Patel, P., Fawcett, A., Clarke, L., Fisher-Vanden, K., Edmonds, J., Kim, S.H., Sands, R, Wise, M. 2009. The distribution and magnitude of emissions mitigation costs in climate stabilization under less than perfect international cooperation: SGM results. Energy Economics 31, S187-S197 (this issue).

Clarke, L., Edmonds, J., Jacoby, H., Pitcher, H., Reilly, J., Richels, R., 2007. Scenarios of greenhouse gas emissions and atmospheric concentrations. Sub-report 2.1A of Synthesis and Assessment Product 2.1 by the U.S. Climate Change Science Program and the Subcommittee on Global Change Research. Department of Energy, Office of Biological \& Environmental Research, Washington, DC., USA. 154 pp.

Clarke, L., Calvin, K., Edmonds, J., Kyle, P., Wise, M., 2009. Technology and international climate policy. Implementing Architectures for Agreement: Addressing Global Climate Change in the Post-Kyoto World. Cambridge University Press. forthcoming.

Cofala, J., Amann, M., Klimont, Z., Kupiainen, K., Höglund-Isaksson, L., 2007. Scenarios of global anthropogenic emissions of air pollutants and methane until 2030. Atmospheric Environment 41, 8486-8499.

den Elzen, M., van Vuuren, D., 2007. Peaking profiles for achieving long-term temperature targets with more likelihood at lower costs. Proceedings of the National Academy of Sciences 104, 17931-17936.

Edmonds, J., Clarke, L., Lurz, J., Wise, M., 2008. Stabilizing $\mathrm{CO}_{2}$ concentrations with incomplete international cooperation. Climate Policy 8, 355-376 [PNNL-SA-16932]

Fisher, B.S., Nakicenovic, N., Alfsen, K., Corfee Morlot, J., de la Chesnaye, F., Hourcade, J.-Ch. Jiang, K., Kainuma, M., La Rovere, E., Matysek, A., Rana, A., Riahi, K., Richels, R., Rose, S. van Vuuren, D., Warren, R., 2007. Issues related to mitigation in the long term context. In: Metz, B., Davidson, O.R., Bosch, P.R., Dave, R., Meyer, L.A. (Eds.), Climate Change 2007: Mitigation. Contribution of Working Group III to the Fourth Assessment Report of the Inter-governmental Panel on Climate Change. Cambridge University Press, Cambridge.

Forest, C.E., Stone, P.H., Sokolov, A.P., Allen, M.R., Webster, M.D., 2002. Quantifying uncertainties in climate system properties with the use of recent climate observations. Science 295, 113-117.

Forster, P., Ramaswamy, V., Artaxo, P., Berntsen, T., Betts, R., Fahey, D.W., Haywood, J., Lean, J., Lowe, D.C., Myhre, G., Nganga, J., Prinn, R., Raga, G., Schulz, M., Dorland, R.V. 2007. Changes in atmospheric constituents and in radiative forcing. In: Solomon, S. Qin, D., Manning, M., Chen, Z., Marquis, M., Averyt, K.B., Tignor, M., Miller, H.L. (Eds.), Climate Change 2007: The Physical Science Basis. Contribution of Working Group I to the Fourth Assessment Report of the Intergovernmental Panel on Climate Change. Cambridge University Press, Cambridge, pp. 129-234.

Gurney, A., Ahammad, H., Ford, M. 2009. The economics of greenhouse gas mitigation: insights from illustrative global abatement scenarios modeling. Energy Economics 31, S174-S186 (this issue).

Keppo, I., O'Neill, B.C., Riahi, K., 2007. Probabilistic temperature change projections and energy system implications of GHG emission scenarios. Technological Forecasting \& Social Change 74, 936-961.

Kheshgi, H., Smith, S., Edmonds, J., 2005. Emissions and Atmospheric CO2 Stabilization: Long-term Limits and Paths. Mitigation and Adaptation Strategies for Global Change, Climate Change and Environmental Policy 10, 213-220. 
Krey, V., Riahi, K. 2009. Implications of delayed participation and technology failure for the feasibility, costs, and likelihood of staying below temperature targetsgreenhouse gas mitigation scenarios for the 21st century. Energy Economics 31, S94-S106 (this issue).

Loulou, R., Labriet, M., Kanudia, A. 2009. Deterministic and stochastic analysis of alternative climate targets under differentiated cooperation regimes. Energy Economics 31, S131-S143 (this issue).

Meehl, G.A., Stocker, T.F., Collins, W.D., Friedlingstein, P., Gaye, A.T., Gregory, J.M., Kitoh, A Knutti, R., Murphy, J.M., Noda, A., Raper, S.C.B., Watterson, I.G., Weaver, A.J., Zhao, Z.-C., 2007. Global climate projections. In: Solomon, S., Qin, D., Manning, M., Chen, Z., Marquis, M., Averyt, K.B., Tignor, M., Miller, H.L. (Eds.), Climate Change 2007: The Physical Science Basis. Contribution of Working Group I to the Fourth Assessment Report of the Intergovernmental Panel on Climate Change. Cambridge University Press, Cambridge, United Kingdom.

Meinshausen, M., 2006. What does a $2{ }^{\circ} \mathrm{C}$ target mean for GHG concentrations? A brief analysis based on multi-gas emission pathways and several climate sensitivity uncertainty estimates. In: Schellnhuber, J.S., Cramer, W., Nakicenovic, N., Wigley, T.M.L., Yohe, G. (Eds.), Avoiding Dangerous Climate Change. Cambridge University Press, Cambridge, UK, pp. 265-280.

Meinshausen, M., Meinshausen, N., Hare, W., Raper, S.C.B., Frieler, K., Knutti, R., Frame, D.J., Allen, M.R., 2009. Greenhouse-gas emission targets for limiting global warming to $2{ }^{\circ} \mathrm{C}$. Nature $458,1158-1162$.

Moss, R., Babiker, M., Brinkman, S., Calvo, E., Carter, T., Edmonds, J., Elgizouli, I., Emori, S., Erda, L., Hibbard, K., Jones, R., Kainuma, M., Kelleher, J., Lamarque, J.F., Manning, M., Matthews, B., Meehl, J., Meyer, L., Mitchell, J., Nakicenovic, N., O'Neill, B., Pichs, R. Riahi, K., Rose, S., Runci, P., Stouffer, R., van Vuuren, D., Weyant, J., Wilbanks, T., van Ypersele, J.P., Zurek, M., 2008. Towards New Scenarios for Analysis of Emissions, Climate Change, Impacts, and Response Strategies. Intergovernmental Panel on Climate Change, Geneva. 132 pp.

Rao, S., Riahi, K., Stehfest, E., van Vuuren, D., Cho, C., den Elzen, M., Isaac, M., van Vliet, J., 2008. IMAGE and MESSAGE scenarios limiting GHG concentration to low levels. Interim Report, IR-08-020, International Institute for Applied Systems Analysis, Laxenburg, Austria

Richels, R., Rutherford, T., Blanford, G., Clarke, L., 2008. Managing the transition to climate stabilization. Climate Policy 7 (5), 409-428.
Russ, P., van Ierland, T. 2009. Insights on different participation schemes to meet climate goals. Energy Economics 31, S163-S173 (this issue).

S.H.Schneider, S.H., M.D.Mastrandrea, M.D., 2005. Probabilistic assessment of "dangerous" climate change and emissions pathways. Proceedings of the National Academy of Sciences of the United States of America 102, 15728-15735.

Smith, K., Haigler, E., 2008. Co-benefits of climate mitigation and health protection in energy systems: scoping methods. Annual Review of Public Health 29, 11-25.

Smith, S., Wigley, T., 2006. Multi-gas forcing stabilization with MiniCAM. Energy Journal 27, 373-391.

Smith, S., Wigley, T., Edmonds, J., 2000. CLIMATE: a new route toward limiting climate change? Science 290, 1109-1110.

Tol, R.S.J. 2009. The feasibility of low concentration targets: an application of FUND. Energy Economics 31, S121-S130 (this issue).

K.E.Trenberth, K.E., P.D.Jones, P.D., P.Ambenje, P., R.Bojariu, R., D.Easterling, D., A.K.Tank, A.K. D.Parker, D., F.Rahimzadeh, F. J.A.Renwick, J.A., M.Rusticucci, M., B.Soden, B., P. Zhai, P., 2007. Observations: surface and atmospheric climate change. In: Solomon, S., Qin, D., Manning, M., Chen, Z., Marquis, M., Averyt, K.B., Tignor, M., Miller, H.L. (Eds.), Climate Change 2007: The Physical Science Basis. Contribution of Working Group I to the Fourth Assessment Report of the Intergovernmental Panel on Climate Change. Cambridge University Press, Cambridge, pp. 235-336.

UNEP Ozone Secretariat, 2006. Handbook for the Montreal Protocol on Substances that Deplete the Ozone Layer7th ed. United Nations Environment Programme (UNEP, Nairobi.

van Vliet, J., den Elzen, M.G.J., van Vuuren, D.P. 2009. Meeting radiative forcing targets under delayed participation. Energy Economics 31, S152-S162 (this issue).

D.van Vuuren, D., M.den Elzen, M., P.Lucas, P., B.Eickhout, B., B.Strengers, B., B.van Ruijven, B., S.Wonink, S., R.Van Houdt, R., 2007. Stabilizing greenhouse gas concentrations at low levels: an assessment of reduction strategies and costs. Climatic Change 81 (2), 119-159.

Wigley, T., Richels, R., Edmonds, J., 2007. Overshoot Pathways to $\mathrm{CO}_{2}$ Stabilization in a Multi-gas Context. In: Schlesinger, M., de la Chesnaye, F., Kheshgi, H., Kolstad, C., Reilly, J., Smith, J., Wilson, T. (Eds.), Human-Induced Climate Change: An Interdisciplinary Perspective. Cambridge University Press, pp. 84-92. 